\title{
Numerical Study on the Local Buckling Behaviour of Bolted Steel Plates in Steel Jacketing
}

\author{
Xiao-liang Xu, Zhou-dao Lu, Ling-zhi Li, and Chang-jiu Jiang \\ Research Institute of Structural Engineering and Disaster Reduction, College of Civil Engineering, \\ Tongji University, 1239 Siping Road, Shanghai 200092, China \\ Correspondence should be addressed to Ling-zhi Li; tjlilingzhi@gmail.com
}

Received 27 September 2016; Revised 5 December 2016; Accepted 25 December 2016; Published 19 January 2017

Academic Editor: Jun Liu

Copyright (c) 2017 Xiao-liang Xu et al. This is an open access article distributed under the Creative Commons Attribution License, which permits unrestricted use, distribution, and reproduction in any medium, provided the original work is properly cited.

A numerical simulation was conducted to investigate the local buckling behaviour of the bolted steel plates in steel jacketing technique. The numerical model was firstly validated by the results of a previous experimental study. Then a parametric study was conducted to investigate the influence of different restraint measures on the local buckling behaviour and the sensitivity of the buckling behaviour to the initial imperfection. Fitted formulae were developed to calculate the structural field capacity of the bolted steel plates, and recommended values of stiffener size were also provided to facilitate the strengthening design of steel jacketing.

\section{Introduction}

Reinforced concrete (RC) members in existing buildings may need to be retrofitted due to defective construction, accidental damage, material degradation, and being imposed higher loads than initial design. Among all of the available retrofitting techniques, external jacketing, which includes jacketing with concrete, steel, and composite such as fibre reinforced polymers (FRPs) [1], is the most convenient method. To bond steel plates or FRPs using adhesive mortar is the most popular technique, but it would lead to premature debonding and peeling failure at the ends of the bonded plates or FRPs [2,3]; thus considerable efforts have been made to suppress and evaluate these kinds of premature failures $[4,5]$. On the other hand, steel plates attached mechanically using anchor bolts are immune to these adverse effects [6-8]. Although attaching steel plates to beam soffits can effectively increase their flexural strength and stiffness, it may lead to overreinforcement and a subsequent serious decrease in ductility [6-9], while attaching steel plates to the side faces of beams by anchor bolts has been proven to possess enhanced flexural strength without a significant reduction in ductility $[10,11]$. Nevertheless, another problem arises; that is, local buckling would occur in the upper compressive region of the bolted steel plates in steel jacketing [11, 12], as shown in Figure 1(a). In the aspect of columns, the same problem occurs when the bolted steel plates are under axial or eccentric compression [13-15], as shown in Figure 1(b).

The local buckling mode of the bolted steel plates in steel jacketing can be seen as a unilateral buckle, since the inward displacement of plates is restrained by the RC beams or columns. Comprehensive experimental studies have been conducted by researchers worldwide to investigate this kind of unilateral buckle. In the field of RC columns strengthened by steel jacketing, Chai et al. [16] encased the critical regions of circular columns with steel jacketing that was bonded to the column using grout, and high load capacity and ductility was obtained because the jacketing was effective in passive confinement. Wang [1] found that local buckling would occur in the plastic hinge area of rectangular RC columns with steel jacketing. Xiao and $\mathrm{Wu}$ [14] applied stiffeners to avoid local buckling of steel jacketing on five rectangular RC columns with different buckling restraint measures, while, in the field of bolted-side-plated (BSP) RC beams, Smith et al. [17] investigated the local buckling behaviour of bolted steel plates, by introducing the so-called local buckling push test that was proposed by Uy and Bradford in their experimental study on composite profiled beams [18]. Su and Zhu [7] investigated the local buckling behaviour in BSP coupling beams and pointed out that the problem could hardly be suppressed by increasing the number of anchor bolts. Li et al. [11] investigated the variation of the overall performance 


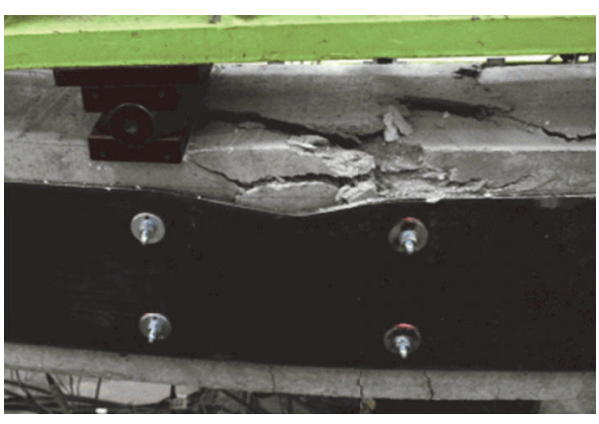

(a)

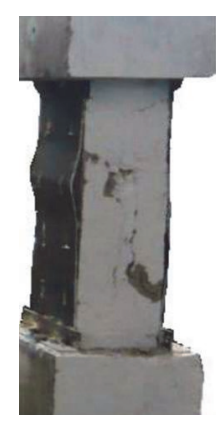

(b)

FIGURE 1: Local buckling of the bolted steel plates in (a) RC beams and (b) columns strengthened using the steel jacketing technique.

of BSP beams after local buckling occurring in the bolted steel plates, and the capacity and ductility decreased by $6 \%$ and $56 \%$, respectively, directly owing to this problem. They [19] also studied the buckling suppressing effect of different restraint measures, which showed that the local buckling deformation of the bolted steel plates can be restricted by employing longitudinal stiffeners and narrower anchor bolts spacing, and the structural field capacity could also be improved.

Since experimental studies of RC structures are expensive thus the number of specimens is usually very limited, researchers conducted finite element analysis (FEA) to extend specimen geometries and kinds of loading conditions. Lubell et al. [20] simulated the postbuckling behaviour of unstiffened steel plate shear wall under cyclic loading with simplified tension field analytical models and provided good predictions of the postyield strength of the specimens. Wright [21] researched the buckling of a long thin plate in contact with a rigid medium unilaterally. Ge and Usami [22] studied the local buckling of short columns with concrete infilled and thin-walled steel and developed an ultimate strength formula for steel plates under uniform compression. For the numerical efforts into the local buckling behaviour of bolted steel plates, Smith et al. [23, 24] developed the buckling formula of bolted steel plates by using Ritz method and by simplifying the boundary conditions of the plates as being simply supported, clamped, and free and carried out a series of simply supported BSP beams to verify the proposed analytical model [25].

Although comprehensive studies have been conducted, it is still lack of a convenient way to estimate the structural field capacity of the bolted steel plates in steel jacketing that can account for the influence of the local buckling effect, especially a simple formula that can be used in the strengthening design practice. Since the number of specimens in experimental study is relatively limited due to expenditure consideration, a parametric study with FEA models built the ABAQUS programme and validated by experimental results was conducted as a feasible tool to investigate the local buckling behaviour of bolted steel plates with different plate thickness, bolt spacing, and different configuration of longitudinal and transverse stiffeners. Fitted formulae and recommended stiffener size were also proposed to facilitate the strengthening design of the steel jacketing technique.
TABLE 1: Constitutive relation of steel.

\begin{tabular}{lccc}
\hline & \multicolumn{2}{c}{ Steel 1 } & \multicolumn{2}{c}{ Steel 2 } \\
Stress/MPa & Strain & Stress/MPa & Strain \\
\hline 302.0 & 0.00000 & 602.0 & 0.00000 \\
302.0 & 0.01856 & 703.0 & 0.00075 \\
370.1 & 0.10928 & 730.0 & 0.00247 \\
404.2 & 0.15464 & 736.0 & 0.00393 \\
438.2 & 0.20000 & 739.0 & 0.00597 \\
438.2 & 1.00000 & 739.0 & 1.00000 \\
\hline
\end{tabular}

\section{Numerical Modelling}

The three-dimensional nonlinear finite element analysis (NLFEA) program ABAQUS was employed to simulate the local buckling behaviour of the bolted steel plates in steel jacketing. The instance assembly in ABAQUS is shown in Figure 2. The size of the concrete block is $360 \mathrm{~mm} \times 400 \mathrm{~mm}$ $\times 150 \mathrm{~mm}$, with six or seven holes used for the installation of anchor bolts. The two investigated steel plates of $300 \mathrm{~mm} \times$ $560 \mathrm{~mm}$ were bolted to its two opposite sides by the anchor bolts $12 \mathrm{~mm}$ in diameter. The bolt spacing is $300 \mathrm{~mm}$ and $100 \mathrm{~mm}$ in transverse and longitudinal directions, respectively. With the restraint of the anchor bolts, the steel plates had no deflection at the connected region of bolts, while the region between bolts can deflect in the transverse direction. And the loading condition can be changed by adjusting the location of the steel hinge on the bearing plates that were fixed to both ends of the bolted steel plates.

Table 1 shows the material constitutive relation of steels that were used in this numerical model, and Table 2 shows the choice of element type and material for each component. The modelling of the main components and the analysis steps will be described in details hereafter in the subsequent subsections.

2.1. Modelling of the Concrete Block. Considering the main purpose of this study is to investigate the local buckling behaviour of the bolted steel plates, so, in this numerical model, the concrete was idealized as an elastic material whose density, Young's modulus, and Poisson's ratio is $2500 \mathrm{Kg} / \mathrm{m}^{3}$, $2.95 \times 10^{10} \mathrm{~N} / \mathrm{m}^{2}$, and 0.2 , respectively. The comparison showed that the model with elastic material for concrete 


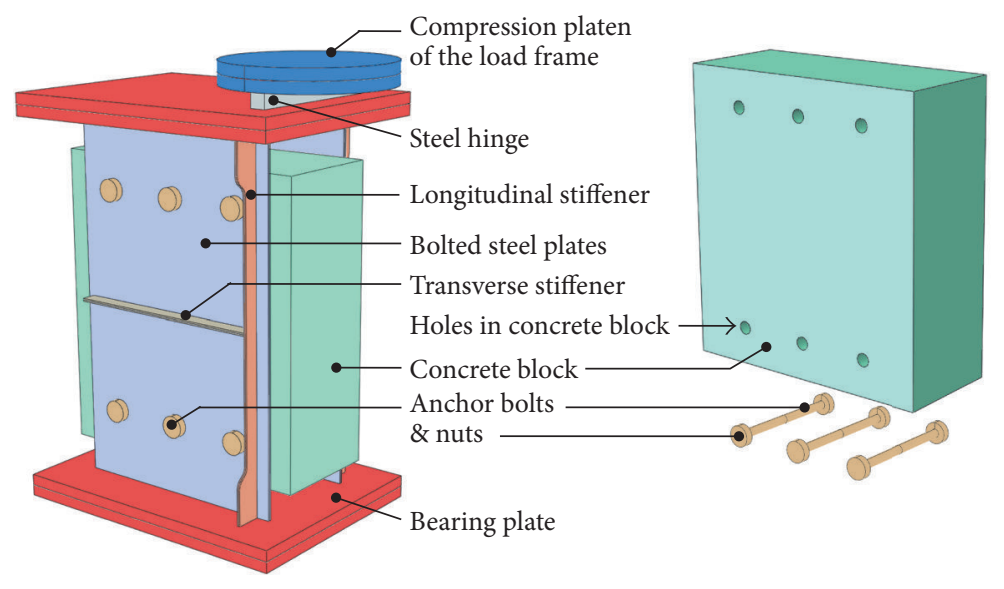

FIGURE 2: Instance assembly of the local buckling test modeling.

TABLE 2: The modelling of main components.

\begin{tabular}{lcc}
\hline Components & Element type & Material \\
\hline Concrete block & C3D8R & Elastic material \\
Steel plates & S4R & Steel 1 \\
Stiffener $(4 \times 20)$ & S4R & Steel 1 \\
Stiffener $(6 \times 25 \&) 8 \times 30$ & S4R & Steel 2 \\
Steel hinges $/$ bolts/nuts & C3D8R & Steel 1 \\
Bearing plates & S4R & Steel 1 \\
\hline
\end{tabular}

had a better convergence, thus, less time-consuming without declining in accuracy, so it is appropriate to employ this elastic simplification. An element size of 0.05 and element type of C3D8R was chosen for the concrete block.

2.2. Modelling of the Steel Plates and Stiffeners. In order to get the best simulating results, all the material used in this model was defined based on the material testing. Table 1 showed material property of steel. And the steel plates and the stiffeners in $4 \mathrm{~mm} \times 20 \mathrm{~mm}$ were assigned the section with material of steel 1 , while the rest of the stiffeners in the other sizes were assigned the section with material of steel 2 . The steel hinge and the anchor bolts and nuts were assigned elements in the type of C3D8R with an element size of 0.05 , while the bolted steel plates, the stiffeners, and the bearing plates were assigned S4R with an element size of 0.05 .

2.3. Modelling of the Bolt Connection. In most of existing numerical studies with ABAQUS, the connection between different parts was simulated by defining an interaction type of "all with self." This simplification could simulate the friction action effectively in most cases but not for the connection in this study, where the precompression was loaded on by tightening the nuts. Therefore, a solution was proposed to simulate the precompression of the anchor bolts, by preshortening the anchor bolts for $0.05 \mathrm{~mm}$ in longitudinal direction after defining the "all with self" between different parts with a friction coefficient 0.15 , and then a longitudinal displacement of $3.5 \mathrm{~mm}$ was imposed on the compression platen to apply concentric or eccentric compression to the bolted steel plates. The measure was proved effective by the subsequent investigation.

2.4. Initial Imperfection. The initial imperfection should be considered because it may have a significant influence in investigation of buckling. It is common to introduce the first buckling mode as the initial imperfection. To get the first buckling mode and use it as the initial imperfection of steel plates, the following progress was conducted in sequence:

(1) Clamp the concrete block and nuts; then conduct a "BUCKLIE Step" analysis for the model, which produces an input file "job-1.inp".

(2) Write the statement of "**Nodefile//U" into the input file "job-1.inp" after "Restart, write, frequency=0", then re-executed the file "job-1.inp" and obtain the file "job-2.fil", which includes the buckling information and modes of the bolted steel plates, as shown in Figure 3.

(3) Redefine the friction connection by preshortening the anchor bolts for $0.05 \mathrm{~mm}$, and impose a longitudinal displacement of $3.5 \mathrm{~mm}$ on the compression platen; then conduct a "Static General Step" analysis by executing the input file "job-1.inp".

(4) Write the statement of "*imperfection, file=joba,sep=1//N, A" into the file "job-1.inp" between "**Boundary" and "* Step"; then the nonlinear analysis can be realized by reexecuting the input file "job-1.inp". The letter " $\mathrm{N}$ " in the statement means introducing the Nth Buckling mode as the initial imperfection. And the letter " $A$ " is the magnitude of the imperfection (usually set to be $10 \%$ of the plate thickness), which will be multiplied with the selected buckling mode and applied to the bolted steel plates automatically in the nonlinear analysis step. 
TABLE 3: The information of specimens.

\begin{tabular}{|c|c|c|c|c|c|}
\hline \multirow{2}{*}{ Number } & \multirow{2}{*}{ Name } & \multirow{2}{*}{ Loading condition } & \multirow{2}{*}{$\begin{array}{l}\text { Thickness of plate } \\
t(\mathrm{~mm})\end{array}$} & \multicolumn{2}{|c|}{ Size and category of stiffeners $(\mathrm{mm} \times \mathrm{mm})$} \\
\hline & & & & Longitudinal & Transverse \\
\hline 1 & C4NN & Axial-compressive (C) & $4.3(4)$ & No $(\mathrm{N})$ & No $(\mathrm{N})$ \\
\hline 2 & E4NN & Eccentric-compressive (E) & $4.3(4)$ & No $(\mathrm{N})$ & No $(\mathrm{N})$ \\
\hline 3 & E6NN & Eccentric-compressive (E) & $5.7(6)$ & No $(\mathrm{N})$ & No $(\mathrm{N})$ \\
\hline 4 & E4AN & Eccentric-compressive (E) & $4.3(4)$ & Bolt fixing $(\mathrm{A})$ & No $(\mathrm{N})$ \\
\hline 5 & E4SN & Eccentric-compressive (E) & $4.3(4)$ & $4 \times 20($ small,$S)$ & No $(\mathrm{N})$ \\
\hline 6 & $\mathrm{E} 4 \mathrm{MN}$ & Eccentric-compressive (E) & $4.3(4)$ & $6 \times 25($ medium,$M)$ & No $(\mathrm{N})$ \\
\hline 7 & E4LN & Eccentric-compressive (E) & $4.3(4)$ & $8 \times 30($ large, $\mathrm{L})$ & No $(N)$ \\
\hline 8 & E4SS & Eccentric-compressive (E) & $4.3(4)$ & $4 \times 20($ small, $S)$ & $4 \times 20($ small,$S)$ \\
\hline
\end{tabular}

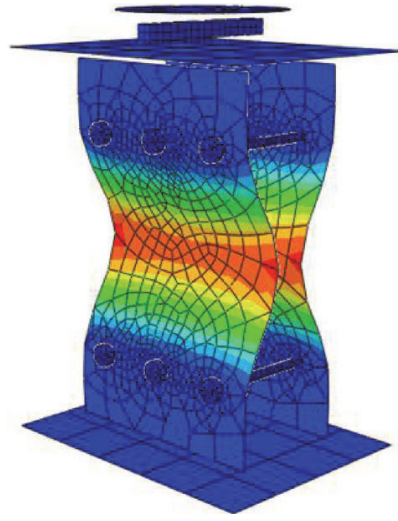

(a)

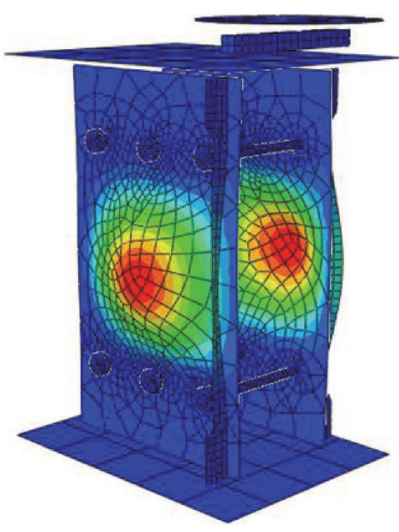

(e)

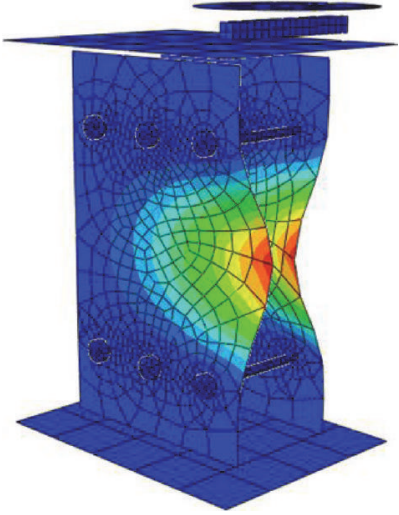

(b)

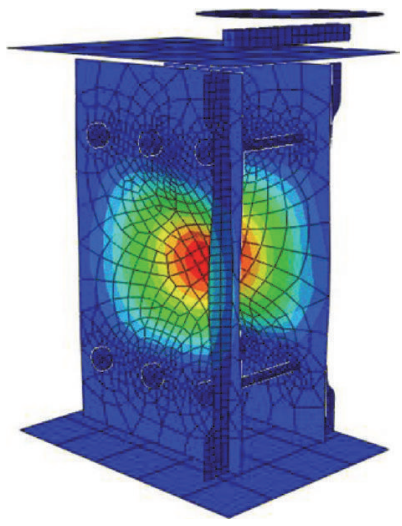

(f)

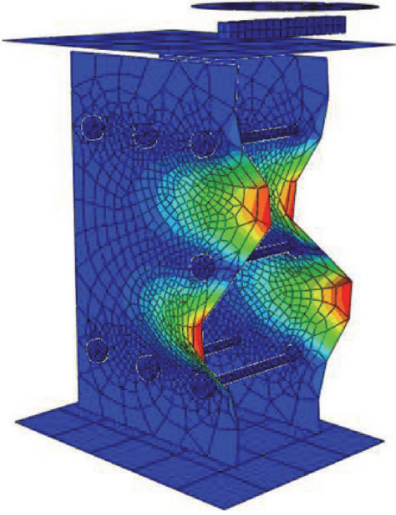

(c)

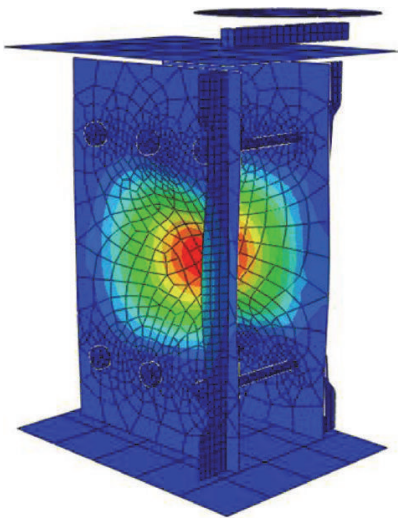

(g)

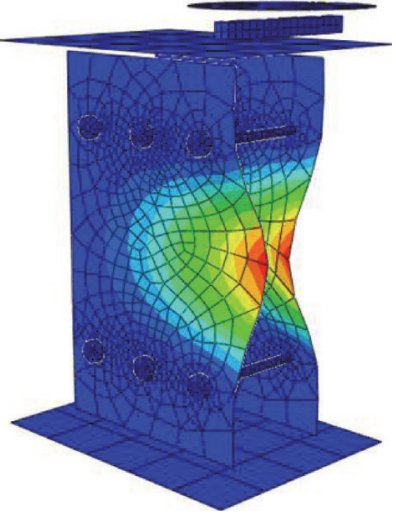

(d)

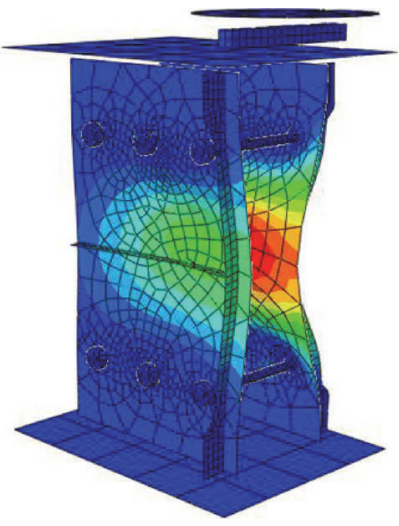

(h)

Figure 3: Buckling modes of each of the specimens (a) C4NN, (b) E4NN, (c) E4AN, (d) E6NN, (e) E4SN, (f) E4MN, (g) E4LN, and (h) E4SS.

\section{Validation of the Numerical Model}

3.1. A Brief Introduction to the Experimental Study. In a previous experimental study [19], eight specimens with different buckling restraint measures were investigated to study how the loading condition, plate thickness, arrangement of longitudinal and transverse stiffeners, and bolt spacing affect the local buckling behaviour of the bolted steel plates. The design drawings and the general information of the specimens are shown in Figure 4 and Table 3, and more details can be found in [19].
3.2. Comparison of the Test and Numerical Results. In order to verify the efficiency and accuracy of the numerical models, comparison between the experimental and numerical results is shown in Figures 5 and 6 and Table 4.

It is shown in Figure 5 that the failure modes derived from the numerical study agree with those observed in the experimental study. There is no significant buckling at the beginning of loading; then the steel plates buckles outwards in lateral direction as the increase of compressive loading; the steel plates finally fails due to lateral buckling as a result of the rapid degradation of stiffness. When the bolted steel plates are 


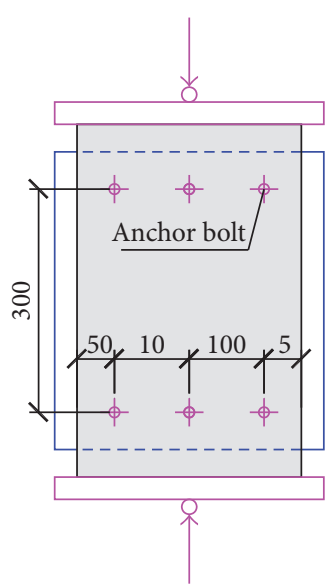

(a)

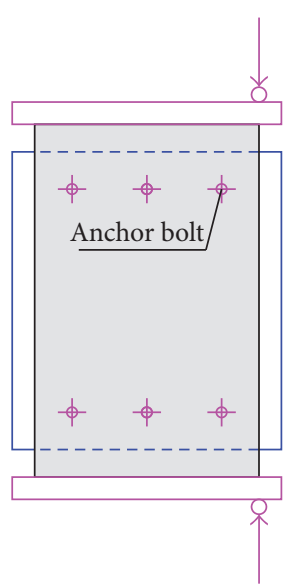

(b)

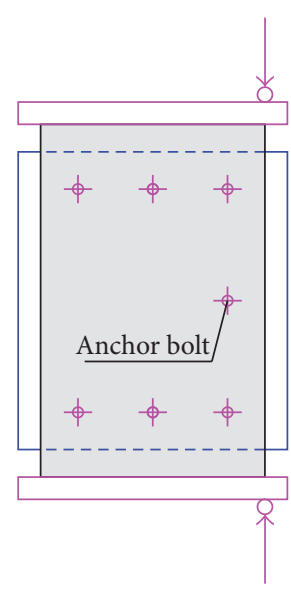

(c)

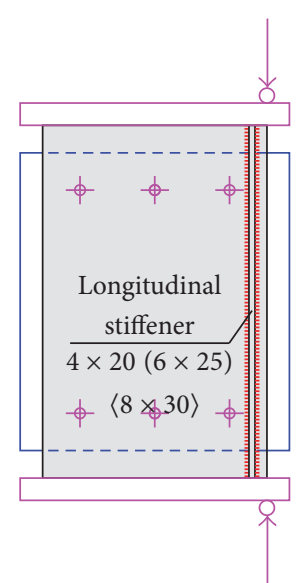

(d)

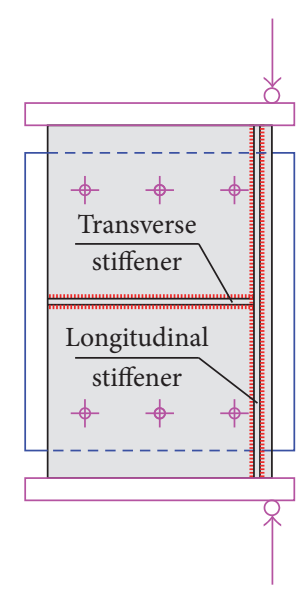

(e)

FIGURE 4: Restrain configuration of specimens (a) C4NN, (b) E4NN (E6NN), (c) E4AN, (d) E4SN (E4MN) 〈E4LN〉, and (e) E4SS.
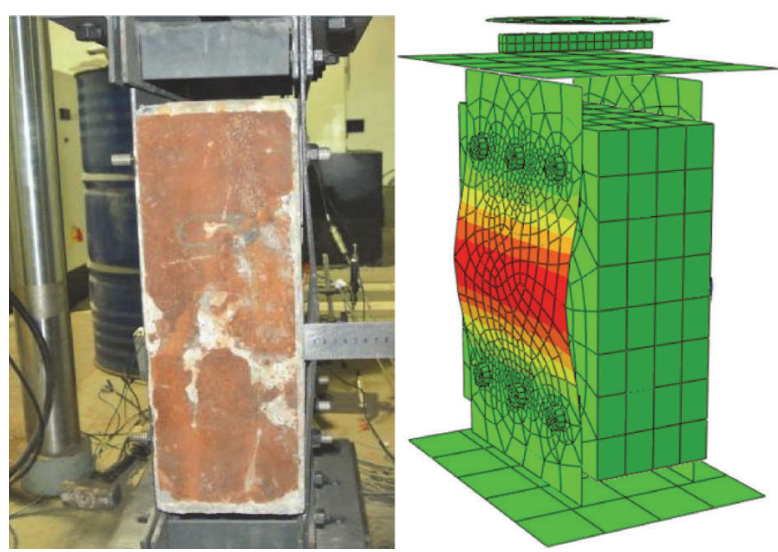

(a)
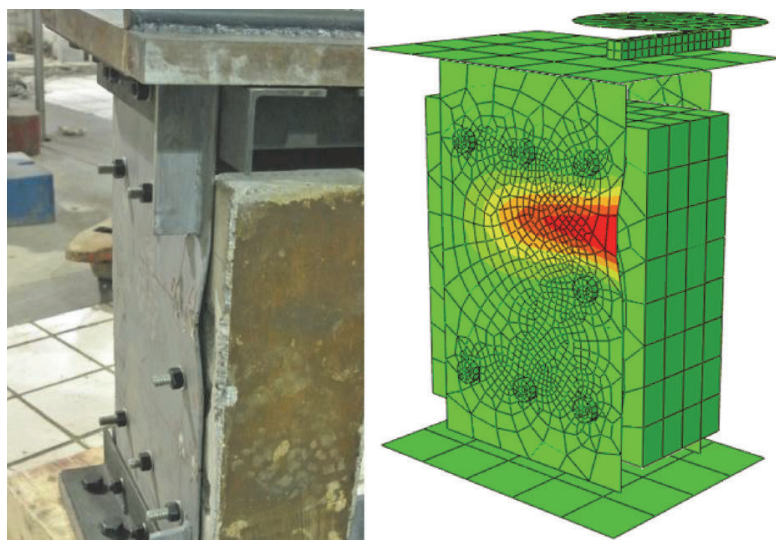

(c)

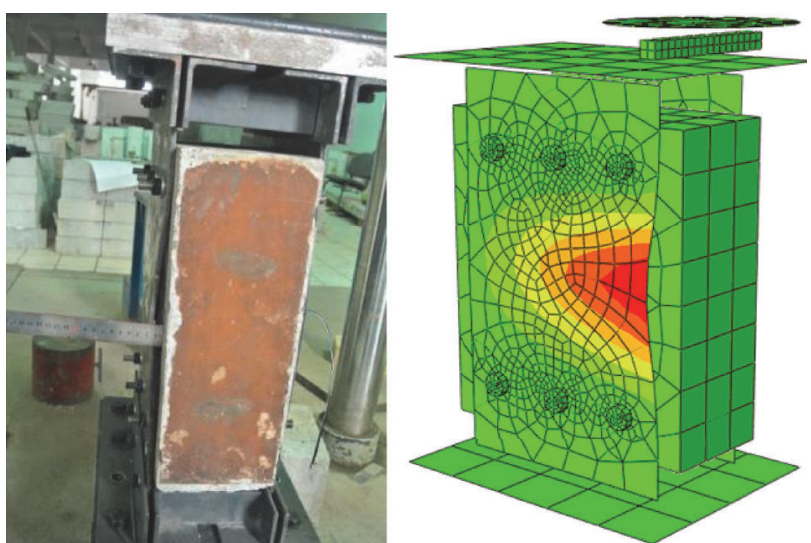

(b)
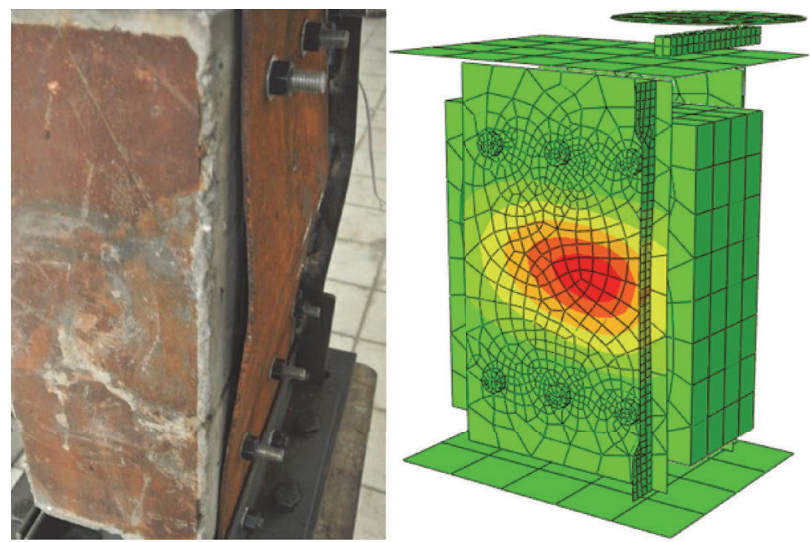

(d)

FIGURE 5: Experimental and simulative failure modes: (a) C4NN, (b) E6NN, (c) E4AN, and (d) E4MN.

under concentric compression, the whole horizontal middle section buckles outwards with a uniform buckling deformation in both the experimental study and the numerical simulation, as shown in Figure 5(a). On the other hand, when the bolted steel plates are under eccentric compression, local buckling only occurs on the compressive edge of the horizontal middle section, as shown in Figure 5(b). When the bolt spacing on the compressive edge is halved, the local 


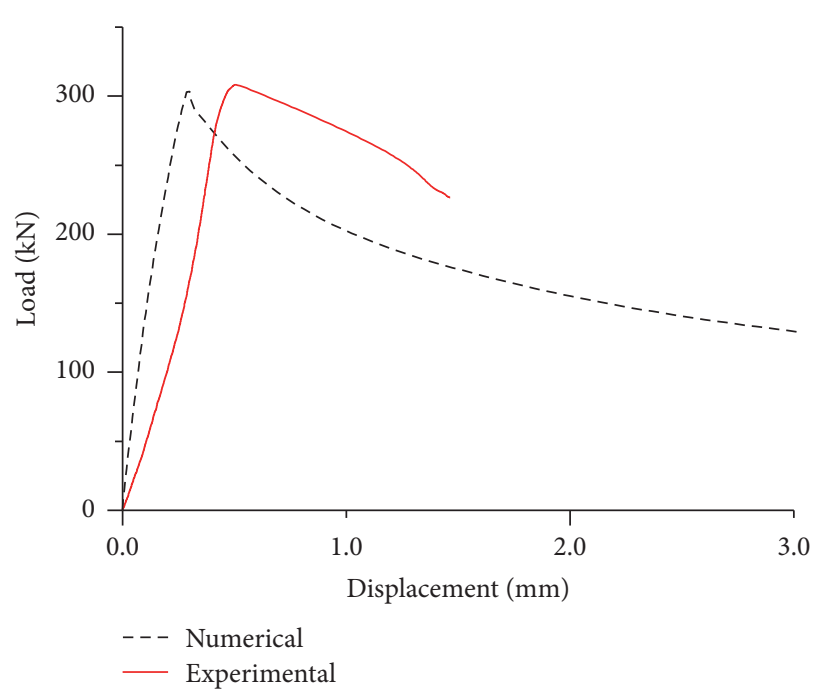

(a)

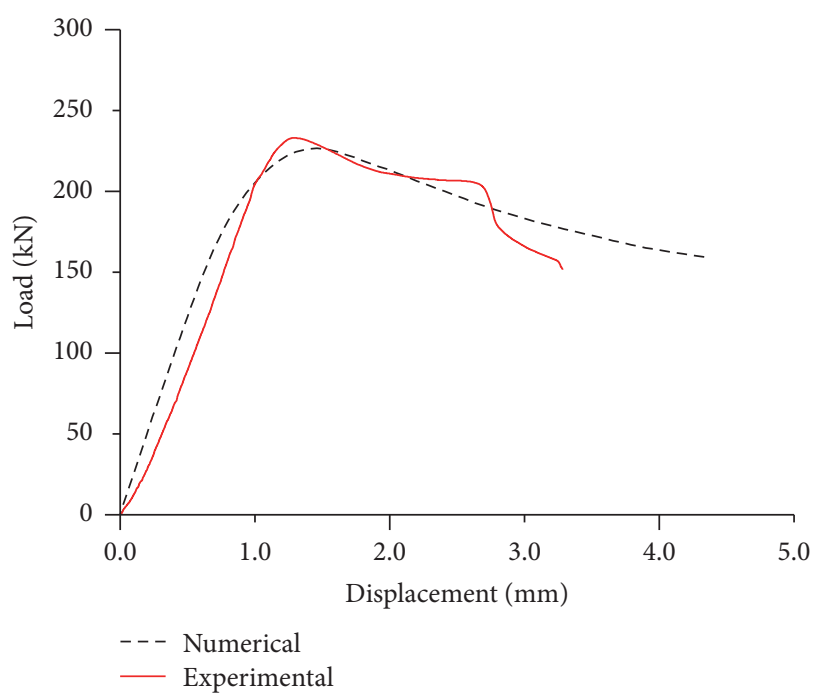

(c)

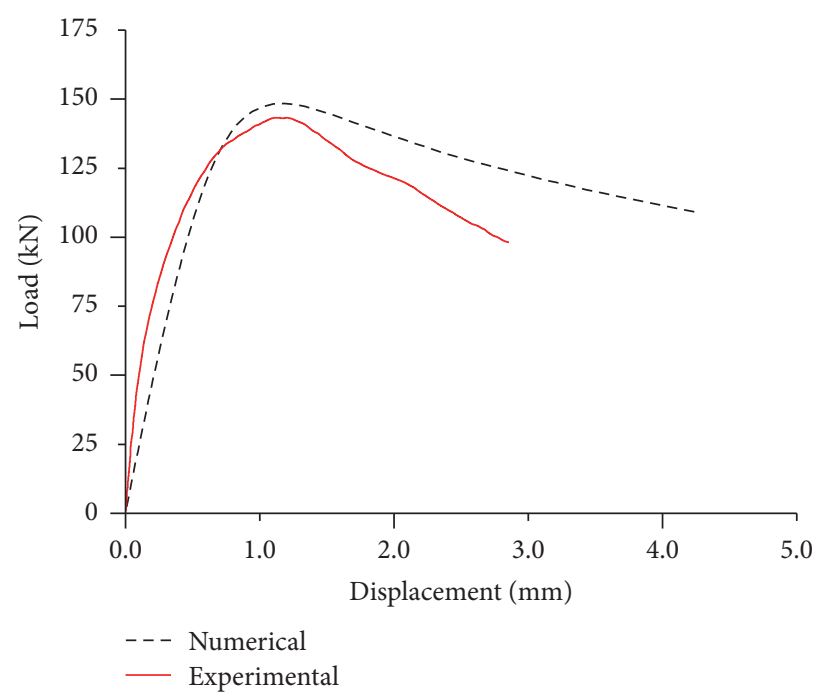

(b)

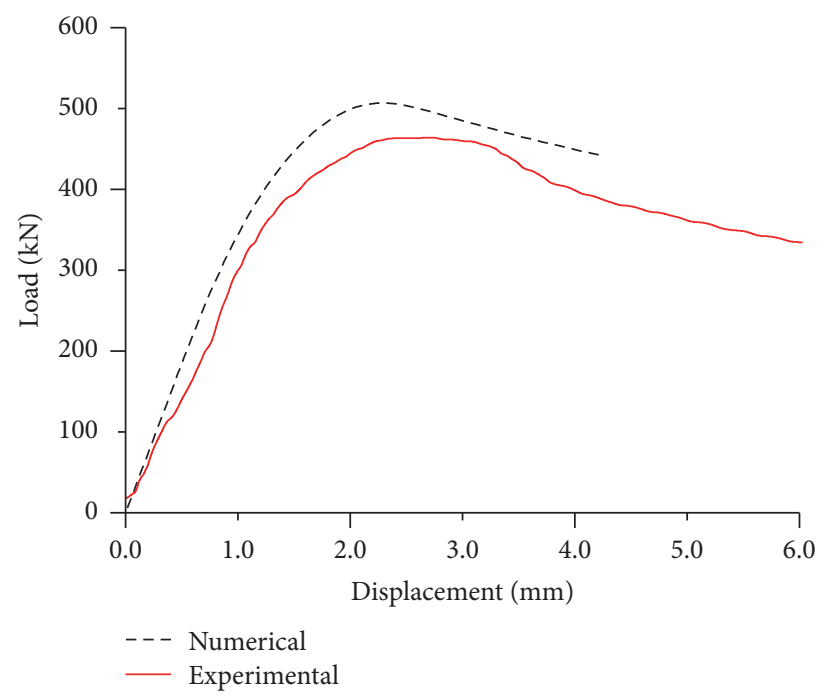

(d)

Figure 6: Experimental and numerical load-displacement curves for (a) C4NN, (b) E4NN, (c) E4AN, and (d) E4MN.

TABLE 4: Comparison of the experimental and numerical field capacity.

\begin{tabular}{lccc}
\hline Specimen & $\begin{array}{c}\text { Experimental } \\
\text { value }(\mathrm{kN})\end{array}$ & $\begin{array}{c}\text { Simulative } \\
\text { value }(\mathrm{kN})\end{array}$ & Error \\
\hline C4NN & 309 & 306 & $1.0 \%$ \\
E4NN & 144 & 149 & $3.5 \%$ \\
E4AN & 233 & 228 & $2.1 \%$ \\
E6NN & 266 & 269 & $1.1 \%$ \\
E4SN & 314 & 347 & $10.5 \%$ \\
E4MN & 464 & 508 & $9.5 \%$ \\
E4LN & 603 & 670 & $11.1 \%$ \\
E4SS & 318 & 350 & $10.1 \%$ \\
\hline
\end{tabular}

buckling shifts upwards (or downwards) to one of the two spans, as shown in Figure 5(c). And if a longitudinal stiffener is employed, the local buckling shifts from the compressive edge to the centre of the horizontal middle section, as shown in Figure 5(d).

Figure 6 shows the comparison of the overall loaddisplacement curves derived from the experimental and numerical studies. And it can be found that the simulation results generally agree with the behaviour of the specimens in test, except for a slight error of both stiffness and peak load; this may be caused by the experimental discrepancy, such as the difference in the roughness of plate and concrete surfaces, the precompression provided by the torque of anchor bolts, the gaps between the bolt shafts, and the holes in the bolted steel plates. The comparison in structural field capacity was listed in Table 4, and the maximum margin of error was 
TABLE 5: Information of models.

\begin{tabular}{|c|c|c|c|c|c|}
\hline \multirow{2}{*}{ Compression } & \multirow{2}{*}{\multicolumn{2}{|c|}{ Restraint measure }} & \multicolumn{3}{|c|}{ Thickness of plates (mm) } \\
\hline & & & 2.0 & 4.3 & 5.7 \\
\hline Concentric & No restr & & $\mathrm{C} 2 \mathrm{NN}$ & C4NN & $\mathrm{C} 6 \mathrm{NN}$ \\
\hline \multirow{8}{*}{ eccentric } & No restı & & $\mathrm{E} 2 \mathrm{NN}$ & $\mathrm{E} 4 \mathrm{NN}$ & E6NN \\
\hline & Bolt d & & $\mathrm{E} 2 \mathrm{AN}$ & E4AN & E6AN \\
\hline & \multirow{3}{*}{$\begin{array}{l}\text { Longitudinal stiffener } \\
\qquad(\mathrm{mm} \times \mathrm{mm})\end{array}$} & $4 \times 20$ & $\mathrm{E} 2 \mathrm{SN}$ & $\mathrm{E} 4 \mathrm{SN}$ & E6SN \\
\hline & & $6 \times 25$ & E2MN & $\mathrm{E} 4 \mathrm{MN}$ & E6MN \\
\hline & & $8 \times 30$ & E2LN & $\mathrm{E} 4 \mathrm{LN}$ & E6LN \\
\hline & \multirow{3}{*}{$\begin{array}{l}\text { Longitudinal and } \\
\text { transverse stiffeners } \\
\quad(\mathrm{mm} \times \mathrm{mm})\end{array}$} & $4 \times 20$ & E2SS & E4SS & E6SS \\
\hline & & $6 \times 25$ & E2MM & $\mathrm{E} 4 \mathrm{MM}$ & E6MM \\
\hline & & $8 \times 30$ & E2LL & E4LL & E6LL \\
\hline
\end{tabular}

$11.1 \%$ and the average was $6.1 \%$. Therefore, the error in the load-displacement curves and the structural field capacity was acceptable, and the FEA model can simulate the local buckling behaviour of the bolted steel plates satisfactorily.

\section{Parametric Study}

Since the accuracy of the numerical model was validated, it is feasible to conduct a more detailed parametric study on the local buckling behaviour of the bolted steel plates, by analysing a series of models with different thickness of steel plates, with or without stiffeners of different sizes.

4.1. A Brief Introduction to the Numerical Models. In this parametric study, twenty-seven models were conducted with different buckling restraint measures. To investigate the effect of the thickness of the bolted steel plates, it was varied from $2.0 \mathrm{~mm}$ to $4.3 \mathrm{~mm}$ and $5.7 \mathrm{~mm}$. Similarly, to calibrate the sensitivity of the buckling behaviour to the initial imperfection, another series of models with the initial imperfection of $1.08 \mathrm{~mm}, 2.15 \mathrm{~mm}, 3.23 \mathrm{~mm}$, and $4.3 \mathrm{~mm}$ were conducted. The detailed information of each model can be found in Table 5, of which the parameters have the same meanings as those in Table 3.

4.2. Effect of Plates Thickness and Bolt Spacing. Several particular models (as shown in Figure 7, whose initial imperfection were all $1.08 \mathrm{~mm}$ ) were investigated to study the influence of plate thickness and bolt spacing on the local buckling behaviour of the bolted steel plates.

It is obvious from Figure 7 that the plate thickness has no significant effect on the failure modes, while narrower bolt spacing due to an additional anchor bolt on the compressive edge can make a very different failure mode by changing one span into two spans; thus the buckling moved into either of the two spans. In the other aspect, the load-displacement curves in Figure 8(a) show that a thicker plate distinctly increases the stiffness, the field capacity, and the longitudinal displacement (which means an improved ductility). However, although narrower bolt spacing can improve the field capacity and the longitudinal displacement (thus the ductility) significantly, it does not affect the stiffness; for instance, the load-displacement curves of E6NN and E6AN in Figure 8(a) generally overlapped with each other at the beginning of loading.

The lateral buckling deformation of three different positions on the bolted steel plates was shown in Figures 8(b)8(d): Point A represents the midpoint of the compressive edge, Point $B$ represents the centre of plate, and Point $C$ represents the midpoint of the tensile edge. It is shown that a thicker plate has no significant influence on the growing trend of the lateral buckling deformation except in large size, but it can decrease the buckling deformation especially when it was a large one. Additionally, in the same plate thickness, narrower bolt spacing can decrease the magnitude and the increase rate of the lateral buckling deformation to a certain extent.

4.3. Effect of Longitudinal and Transverse Stiffeners. Similarly, the influence of different arrangement of stiffeners on the buckling behaviour of the bolted steel plates was investigated by comparing the models with stiffeners in variable sizes and different categories. Only the models with plate thickness of $4.3 \mathrm{~mm}$ and initial imperfection of $1.08 \mathrm{~mm}$ were illustrated for simplicity.

Figure 9 shows the deformation distribution diagrams, which demonstrate that the longitudinal stiffener can visibly decrease the lateral buckling deformation of the plates and transfer the region of buckling from compressive edge of the plates to the centre even to the tensile edge (as shown in Figures 9(a)-9(c)), while the transverse stiffener can only decrease the buckling deformation of the central region of the plates and transfer the region of buckling to the upward region of the transverse stiffener (as shown in Figures 9(c) and $9(\mathrm{~d})$ ). And it is also evident that the bigger stiffener has a stronger buckling restraint.

The load-displacement curves shown in Figure 10(a) indicate that the longitudinal stiffeners can distinctly improve the stiffness and the field capacity, and an increase in stiffener size led to a more obvious improvement. Besides, it is also shown that the longitudinal displacement at the peak load increases. The transverse stiffeners, by contrast, do not improve the stiffness obviously, although they can improve 


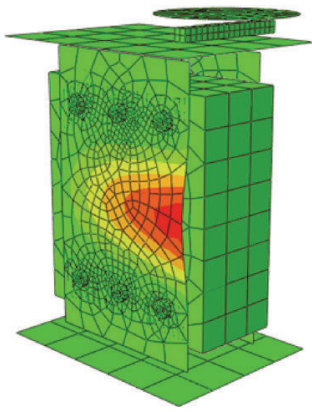

(a) $\mathrm{E} 2 \mathrm{NN}$

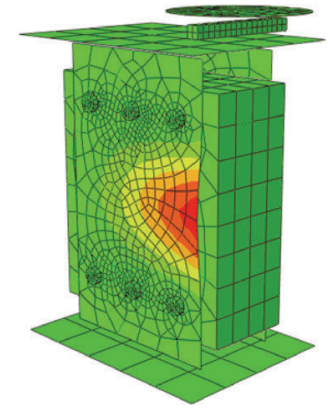

(b) $\mathrm{E} 4 \mathrm{NN}$

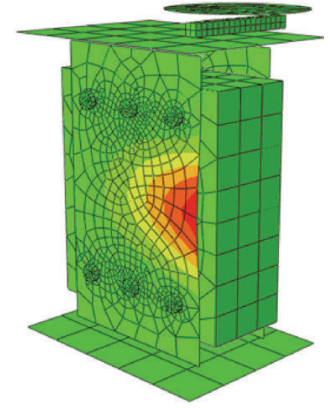

(c) $\mathrm{E} 6 \mathrm{NN}$

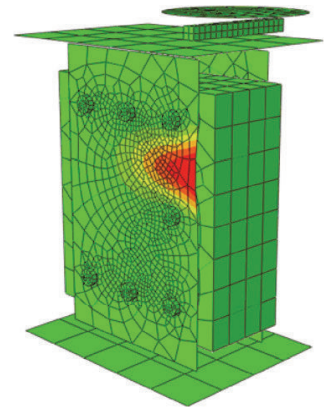

(d) $\mathrm{E} 4 \mathrm{AN}$

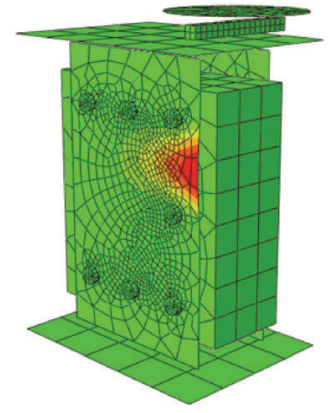

(e) E6AN

FIGURE 7: Failure modes of models with different plate thickness and narrower bolt densification: (a) E2NN, (b) E4NN, (c) E6NN, (d) E4AN, and (e) E6AN.

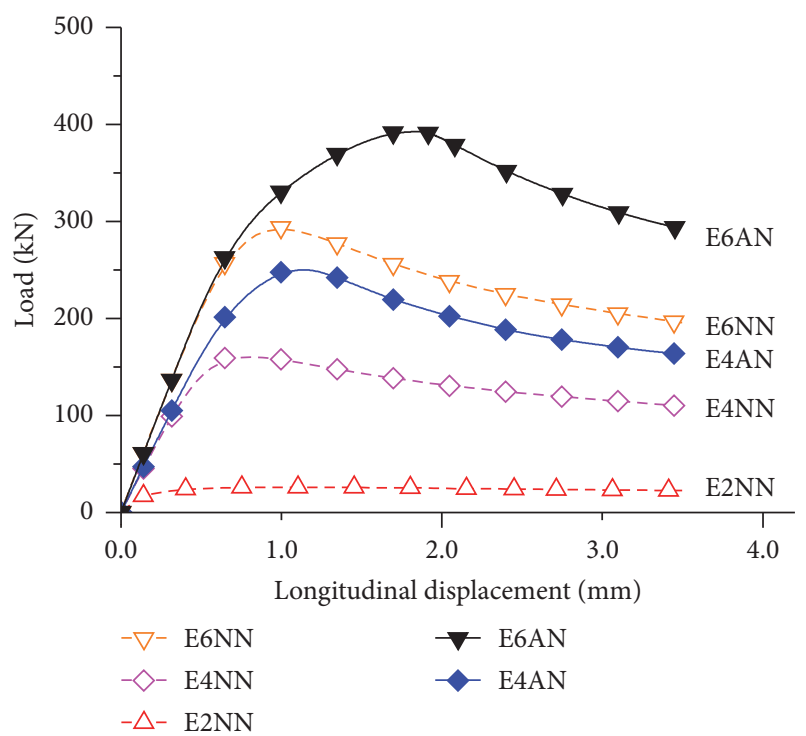

(a)

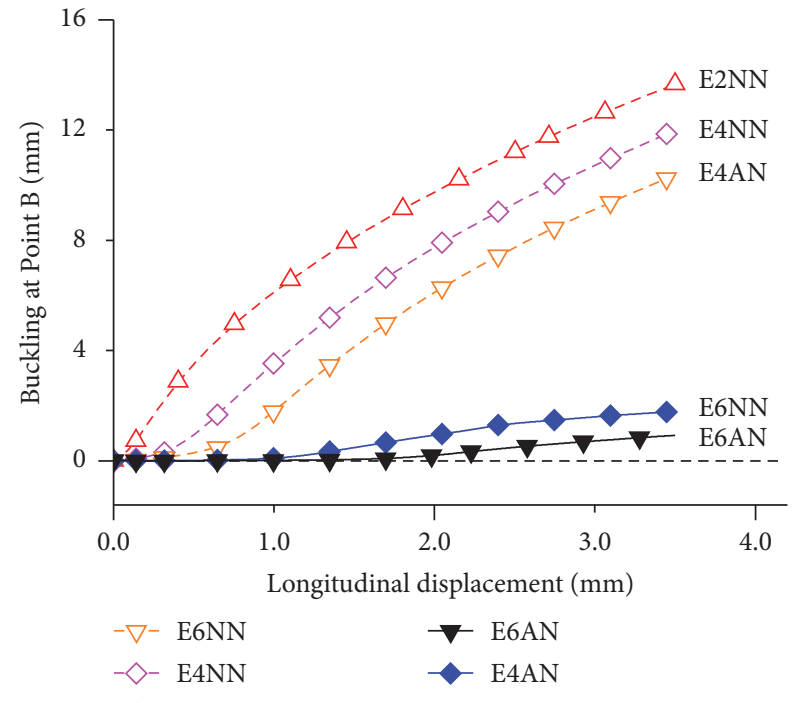

(c)

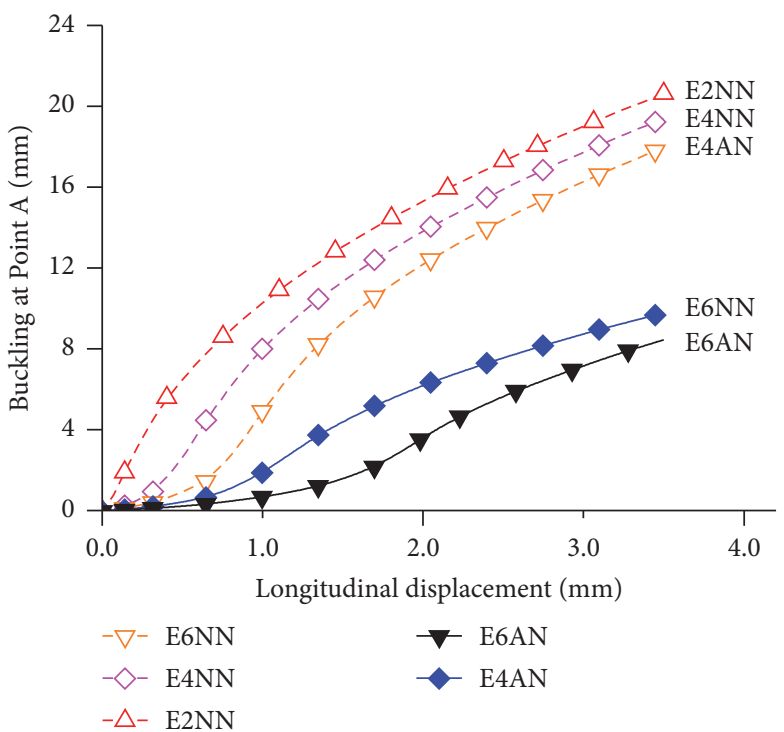

(b)

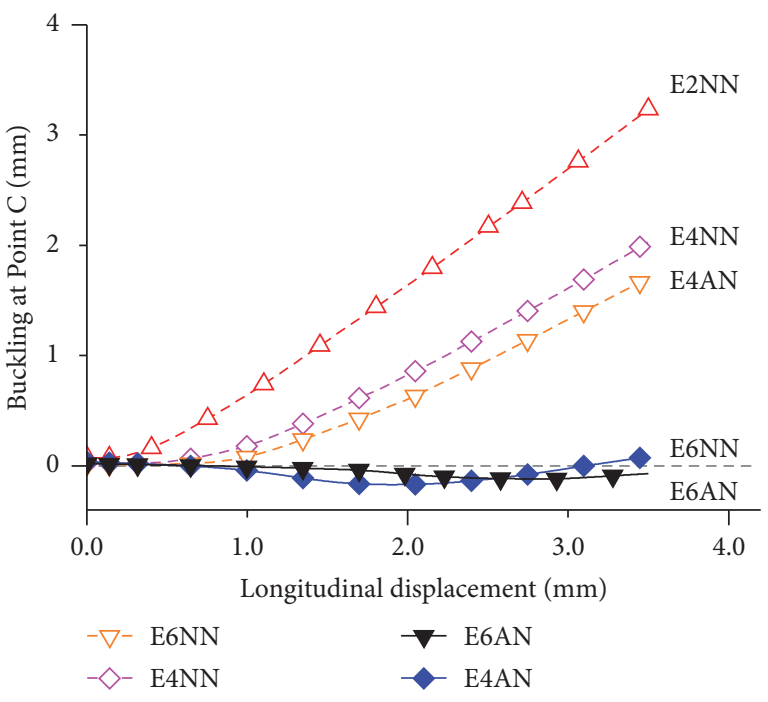

(d)

Figure 8: Load-displacement and buckling-displacement curves 1: (a) load-displacement curves; buckling-displacement curves at (b) Point A, (c) Point B, and (d) Point C. 


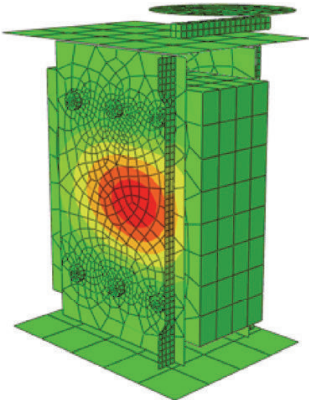

(a)

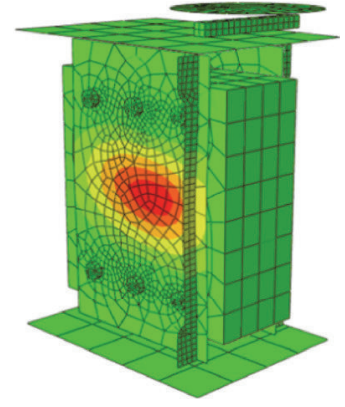

(b)

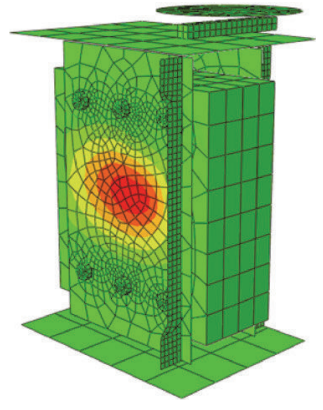

(c)

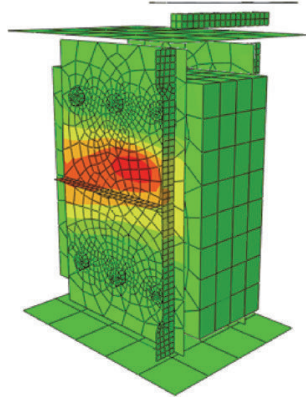

(d)

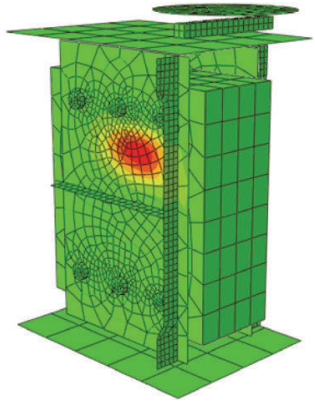

(e)

Figure 9: Failure modes of models with arranging different stiffeners: (a) E4SN, (b) E4MN, (c) E6LN, (d) E4MM, and (e) E4LL.

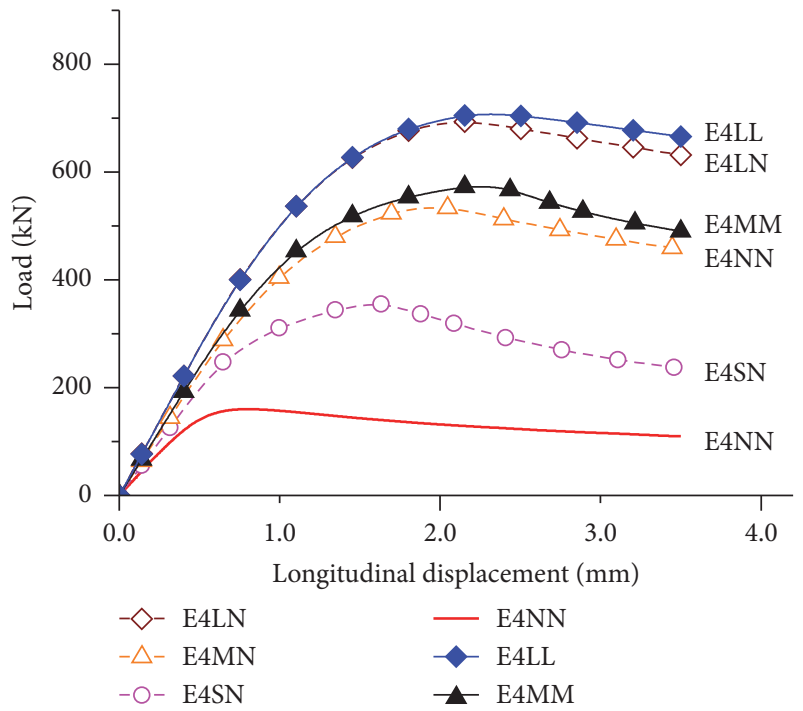

(a)

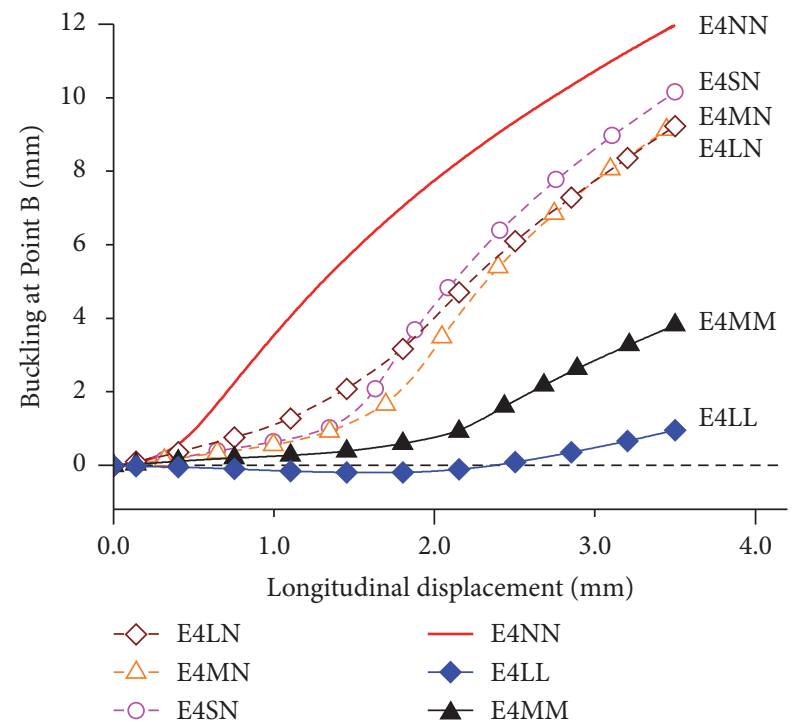

(c)

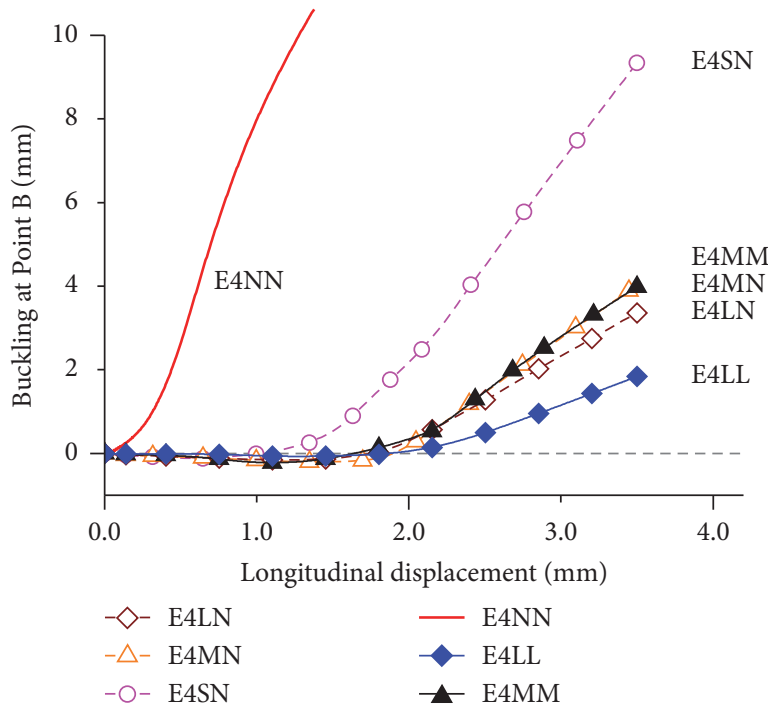

(b)

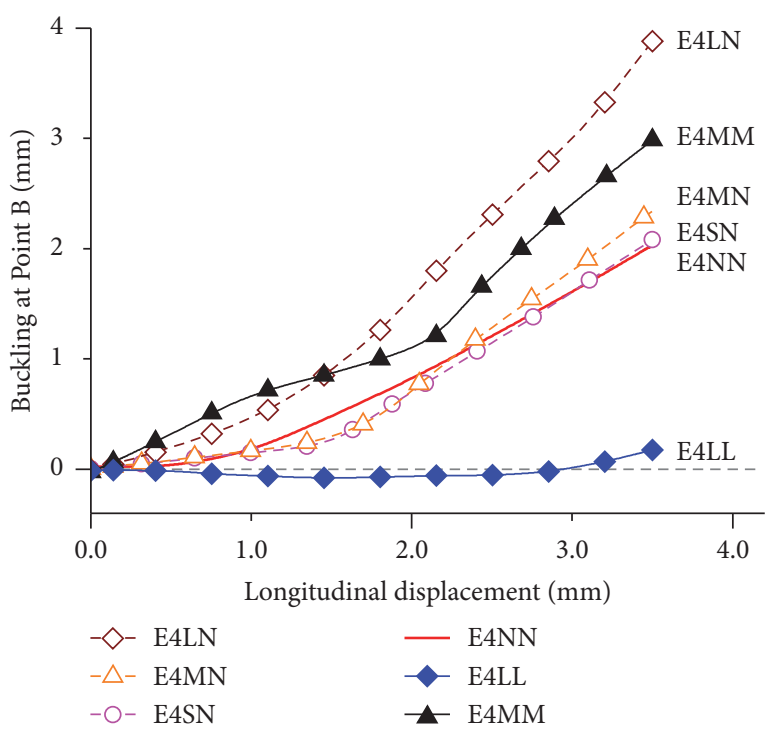

(d)

FIGURE 10: Load-displacement and buckling-displacement curves 2: (a) load-displacement curves; buckling-displacement curves at (b) Point A, (c) Point B, and (d) Point C. 


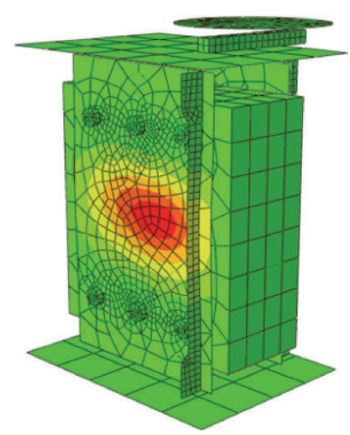

(a) $1.08 \mathrm{~mm}$

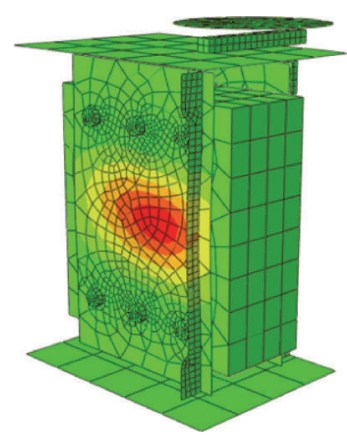

(b) $2.15 \mathrm{~mm}$

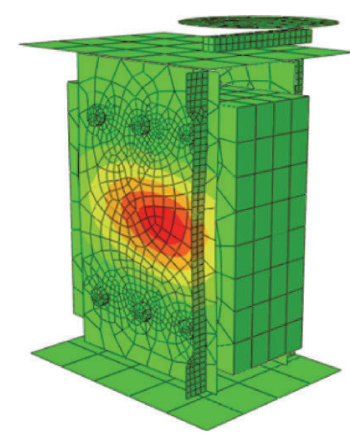

(c) $3.23 \mathrm{~mm}$

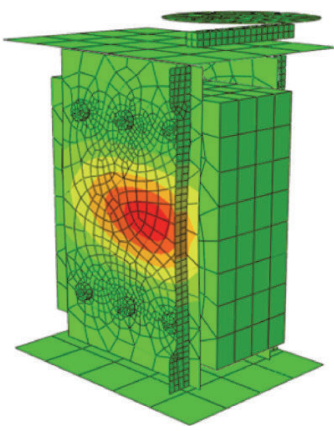

(d) $4.30 \mathrm{~mm}$

FIGURE 11: Failure modes of models with different initial imperfection.

the field capacity in a certain degree; for instance, the loaddisplacement curves of E4LN and E4LL in Figure 10(a) generally overlapped with each other at the beginning of loading.

The development of the lateral buckling deformation in Figures 10(b)-10(d) demonstrates that the longitudinal stiffeners effectively decrease buckling deformation at Point A (the midpoint on the compressive edge) but cause no obvious decrease at Point $B$ (the centre of the plate) and even increase the buckling deformation at Point $\mathrm{C}$ (the midpoint on the tensile edge) when it is a large one. By contrast, arranging transverse stiffeners do not decrease the buckling deformation at Point $\mathrm{A}$ in a visible way when it have already arranged longitudinal stiffeners, and only a big transverse stiffener can lead to an obvious decrease in the buckling deformation at Point C, although it causes a substantial decrease in Point $B$ at the centre of the plate.

4.4. Sensitivity to Initial Imperfection. To investigate the sensitivity of the buckling behaviour of the bolted steel plates to the initial imperfection, the buckling behaviour of models with a series of initial imperfections, that is, $1.08 \mathrm{~mm}$, $2.15 \mathrm{~mm}, 3.23 \mathrm{~mm}$, and $4.3 \mathrm{~mm}$, was compared.

It is shown from Figure 11 that the failure modes were almost the same for the models with different imperfection; thus it is insensitive to the magnitude of initial imperfection.

In the aspect of the load-displacement curves, a high coherence between curves with different initial imperfection is shown in Figure 12(a), which nearly overlapped with each other at the beginning of loading. It is shown that the field capacity is insensitive to the initial imperfection, although a smaller initial imperfection leads to a little higher field capacity. And the development of the lateral buckling deformation in Figures 12(b)-12(d) indicates that a bigger initial imperfection has no substantial influence on the growing trend though it can increase the lateral buckling deformation in a certain degree. So the buckling behaviour of the bolted steel plates is insensitive to initial imperfection.

\section{Design Recommendation}

\subsection{Formula Fitting}

5.1.1. Components of the Structural Field Capacity. Based on the numerical models, a formula can be built to fit the structural field capacity of the bolted steel plates that considers the difference in restraint measures. Since the arrangement of longitudinal stiffeners can substantially improve the structural field capacity, for simplicity the improvement can be divided into two parts: the bearing capacity of the stiffeners and the enhancement to the steel plates beneficial from the buckling restraint of the stiffeners. Therefore, the structural field capacity $F$ can be divided into three parts: the capacity of the bolted steel plates $\left(F_{0}\right)$, the yield strength of the longitudinal stiffeners $\left(F_{1}\right)$, and the enhancement due to the buckling restraint of the longitudinal stiffeners $\left(F_{2}\right)$, as follows:

$$
F=F_{0}+F_{1}+F_{2} .
$$

(1) According to the buckling theory, the capacity of the bolted steel plates $\left(F_{0}\right)$ is equal to the value of structural field capacity without any restraint measure and is related to the value of Young's modulus $(E)$, the breadth and thickness $(B$ $\& t$ ) of the bolted steel plates, and the bolt spacing $(L)$. It can be assumed in the form of (2) by taking E4NN (whose field capacity is $149 \mathrm{kN}$ ) as reference. And solving (3) by introducing the related parameters (i.e., $E=210 \mathrm{GPa}, B=$ $0.3 \mathrm{~m}, L=0.3 \mathrm{~m}$, and $t=4.3 \mathrm{~mm}$ ) yields $\gamma_{0}=0.2713$.

$$
\begin{aligned}
& F_{0}=\gamma_{0} \times \frac{\pi^{2} E B t^{3}}{L^{2}} \times\left(\frac{B}{0.3}\right)^{x}\left(\frac{L}{0.3}\right)^{y}\left(\frac{t}{0.0043}\right)^{z}, \\
& F_{0}=\gamma_{0} \times \frac{\pi^{2} E B t^{3}}{L^{2}}=149 \mathrm{kN} .
\end{aligned}
$$

(2) According to the theory in material mechanics, the capacity of the longitudinal stiffeners $\left(F_{1}\right)$ is related to the sectional size of the stiffeners and the field strength of steel, thus in the form of

$$
F_{1}=2 a b f_{y} .
$$




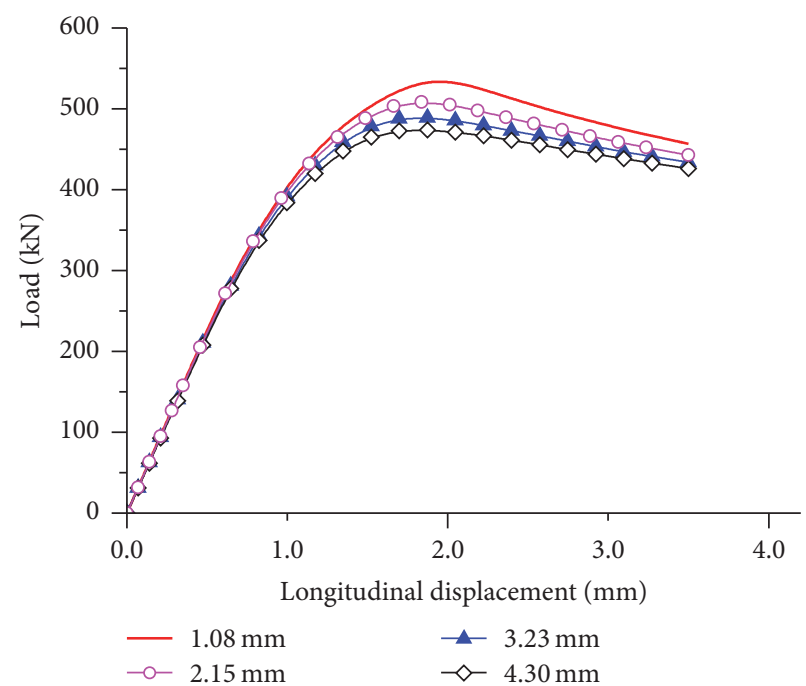

(a)

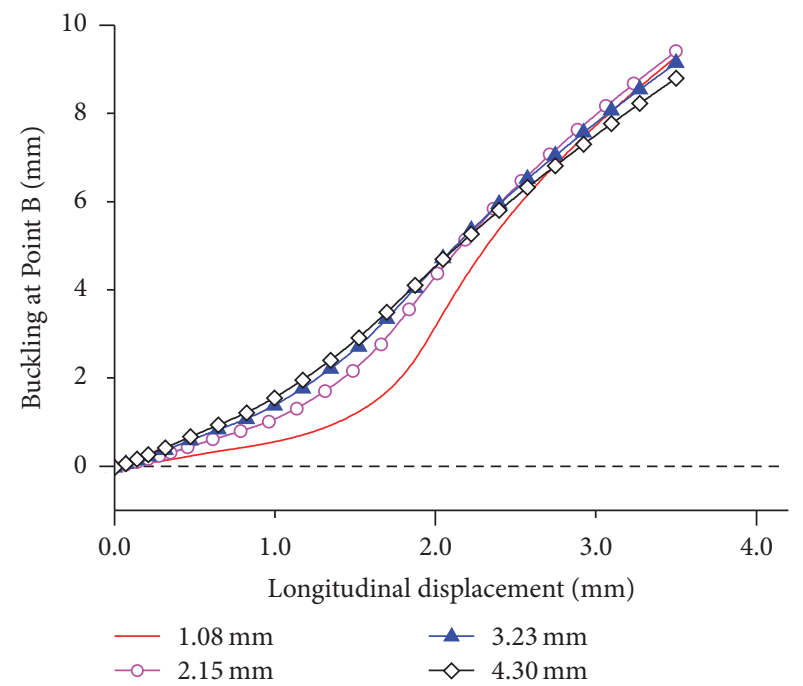

(c)

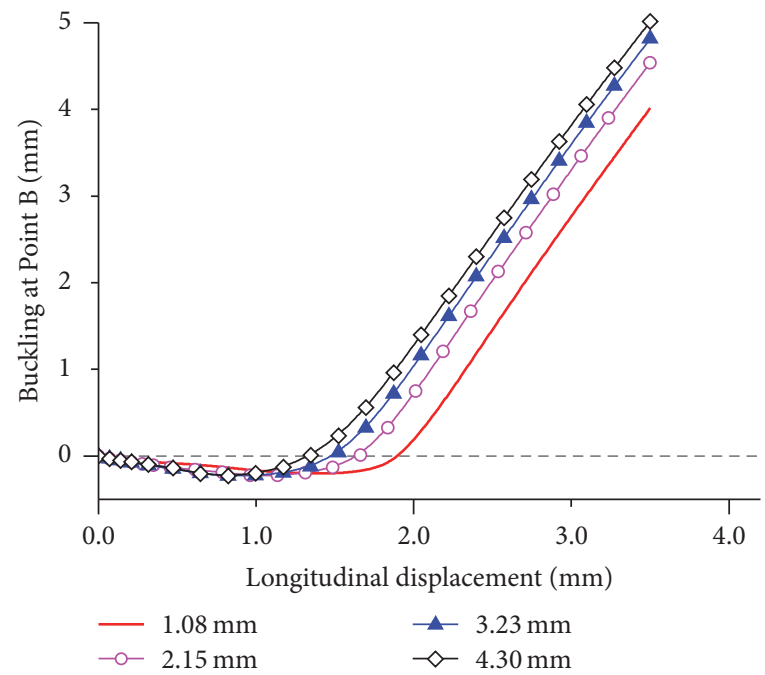

(b)

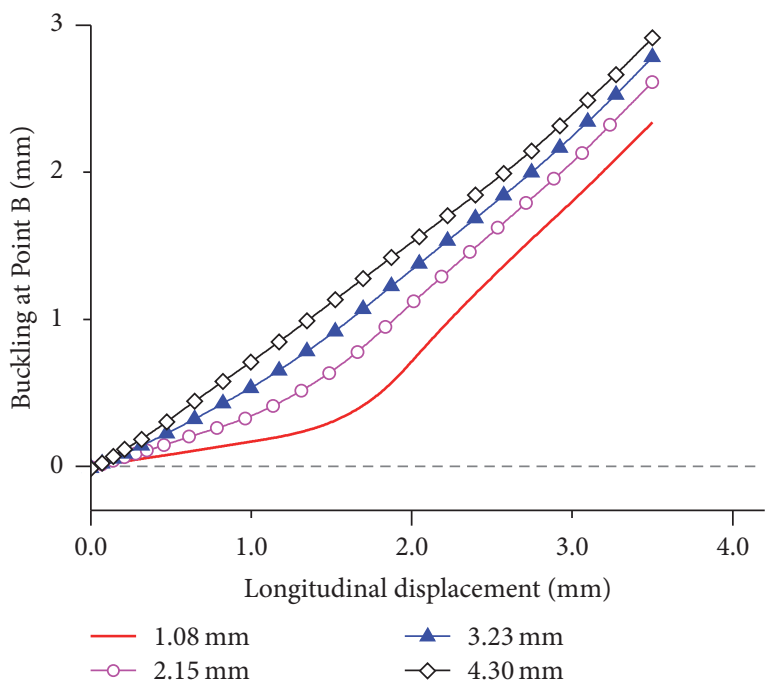

(d)

FIGURE 12: Load-displacement and buckling-displacement curves 3: (a) load-displacement curves; buckling-displacement curves at (b) Point A, (c) Point B, and (d) Point C.

(3) The enhancement benefitting from the buckling restraint of the longitudinal stiffeners $\left(F_{2}\right)$ may be related to the width and thickness ( $a$ and $b$ ) of the stiffener and the thickness of the steel plate $(t)$. Besides, the breadth of the bolted steel plate $(B)$ and the bolt spacing $(L)$ may possibly affect the value of $\left(F_{2}\right)$. So the formula can be defined as follows. And similar to $F_{0}$, taking $\mathrm{E} 4 \mathrm{SN}\left(F_{2}=127 \mathrm{kN}\right)$ as reference and solving (6) yield $\gamma_{2}=0.2312$.

$$
\begin{aligned}
& F_{2} \\
& =\gamma_{2} \times \frac{\pi^{2} E B t^{3}}{L^{2}} \\
& \quad \times\left(\frac{a}{0.004}\right)^{j}\left(\frac{b}{0.02}\right)^{k}\left(\frac{B}{0.3}\right)^{l}\left(\frac{L}{0.3}\right)^{m}\left(\frac{t}{0.0043}\right)^{n},
\end{aligned}
$$

$$
F_{2}=\gamma_{2} \times \frac{\pi^{2} E B t^{3}}{L^{2}}=127 \mathrm{kN}
$$

5.1.2. Solution of the Undetermined Coefficients. To solve the undetermined coefficient $x$ in (2), a series of models are investigated by adjusting the breadth of the bolted steel plates $(B=0.25,0.275,0.3,0.325$, and $0.35 \mathrm{~m})$ and keeping the other parameters the same as those of E4NN (i.e., $E=210 \mathrm{GPa}, B=$ $0.3 \mathrm{~m}, L=0.3 \mathrm{~m}$, and $t=4.3 \mathrm{~mm}$ ). Substituting $E, B, L$, and $t$ into (2) gives an inconsistent equation series as follows:

$$
\begin{array}{r}
124 \times\left(\frac{0.25}{0.3}\right)^{x}=141, \\
137 \times\left(\frac{0.275}{0.3}\right)^{x}=146,
\end{array}
$$


TABLE 6: Comparison of the field capacities derived from the theoretical and numerical studies.

\begin{tabular}{|c|c|c|c|c|c|c|c|c|}
\hline Number & $t(\mathrm{~mm})$ & $B(\mathrm{~mm})$ & $L(\mathrm{~mm})$ & Longitudinal stiffener & Transverse stiffener & $F_{\text {num }}(\mathrm{kN})$ & $F_{\text {the }}(\mathrm{kN})$ & Errors \\
\hline 1 & 4.3 & 300 & 300 & $4 \times 20$ & - & 324.3 & 324 & $0.1 \%$ \\
\hline 2 & 4.3 & 300 & 300 & $4 \times 20$ & $4 \times 20$ & 338.3 & 350 & $3.3 \%$ \\
\hline 3 & 4.3 & 300 & 300 & $6 \times 25$ & - & 513.3 & 508 & $1.0 \%$ \\
\hline 4 & 4.3 & 300 & 300 & $6 \times 25$ & $6 \times 25$ & 530.2 & 530 & $0.0 \%$ \\
\hline 5 & 4.3 & 300 & 300 & $8 \times 30$ & - & 663.9 & 670 & $0.9 \%$ \\
\hline 6 & 4.3 & 300 & 300 & $8 \times 30$ & $8 \times 30$ & 683.5 & 682 & $0.2 \%$ \\
\hline 7 & 5.7 & 300 & 300 & $4 \times 20$ & - & 446.1 & 448 & $0.4 \%$ \\
\hline 8 & 5.7 & 300 & 300 & $4 \times 20$ & $4 \times 20$ & 460.3 & 462 & $0.4 \%$ \\
\hline 9 & 5.7 & 300 & 300 & $6 \times 25$ & - & 635.4 & 658 & $3.4 \%$ \\
\hline 10 & 5.7 & 300 & 300 & $6 \times 25$ & $6 \times 25$ & 652.6 & 679 & $3.9 \%$ \\
\hline 11 & 5.7 & 300 & 300 & $8 \times 30$ & - & 786.5 & 823 & $4.4 \%$ \\
\hline 12 & 5.7 & 300 & 300 & $8 \times 30$ & $8 \times 30$ & 806.4 & 840 & $4.0 \%$ \\
\hline 13 & 5.6 & 310 & 340 & $5.6 \times 24$ & - & 437.1 & 456 & $4.1 \%$ \\
\hline
\end{tabular}

$$
\begin{array}{r}
149 \times\left(\frac{0.3}{0.3}\right)^{x}=149, \\
161 \times\left(\frac{0.325}{0.3}\right)^{x}=156, \\
174 \times\left(\frac{0.35}{0.3}\right)^{x}=162 .
\end{array}
$$

The equation series can be solved by a least square fitting (LSF); thus the undetermined coefficient $x$ can be solved as $x=-0.60$.

Similarly, other series of models can also be investigated by adjusting the bolt spacing $(L)$ and the thickness of steel plates $(t)$ to solve the undetermined coefficients $y$ and $z$, respectively, as $y=1.02$ and $z=-0.91$. Therefore, (2) can be determined as follows:

$$
\begin{aligned}
F_{0}= & 0.2713 \times \frac{\pi^{2} E B t^{3}}{L^{2}} \\
& \times\left(\frac{B}{0.3}\right)^{-0.60}\left(\frac{L}{0.3}\right)^{1.02}\left(\frac{t}{0.0043}\right)^{-0.91} .
\end{aligned}
$$

In the same way, the undetermined parameters of (5) can also be solved as $j=0.20, k=0.49, l=-0.75, m=2.70$, and $n=-2.94$, by sequentially changing the thickness and breadth of the longitudinal stiffeners ( $a$ and $b$ ), the breadth and the thickness of the bolted steel plates $(B \& t)$, and the bolt spacing $(L)$. After that, the formula of $F_{2}$ can be expressed as follows:

$$
\begin{gathered}
F_{2}=0.2312 \times \frac{\pi^{2} E B t^{3}}{L^{2}} \times\left(\frac{a}{0.004}\right)^{0.20}\left(\frac{b}{0.02}\right)^{0.49} \\
\cdot\left(\frac{B}{0.3}\right)^{-0.75}\left(\frac{L}{0.3}\right)^{2.70}\left(\frac{t}{0.0043}\right)^{-2.94} \cdot
\end{gathered}
$$

In addition to the longitudinal stiffeners, the transverse stiffeners can also improve the structural field capacity to a certain extent. Considering the fact that, under normal conditions, the transverse stiffeners are always arranged together with the longitudinal ones with the same sectional size, so it is reasonable to consider the improvement of the transverse stiffeners by introducing an amplification coefficient $\alpha$ to the enhancement of the longitudinal stiffeners $\left(F_{2}\right)$. And thereby the total field capacity $(F)$ can be expressed more accurately in a modified form as

$$
F=F_{0}+F_{1}+\alpha F_{2}
$$

By investigating a series of models in different combinations of stiffeners, the undetermined coefficient $\alpha$ can also be solved as $\alpha=1.11$. And, for those without transverse stiffeners, $\alpha=1.0$.

In order to test the degree fitting of (10), a series of models with different buckling restraint measures were built and their field capacities derived from the numerical FEA simulation $\left(F_{\text {num }}\right)$ and those computed using the aforementioned formulae $\left(F_{\text {the }}\right)$ are compared in Table 6 . It is shown that the errors between the calculated and the numerical results agree with each other very well. The maximum error was $4.4 \%$ and the average error is $2.0 \%$. So the fitted formulae have a high fitting degree thus being reasonable and authentic.

5.1.3. Verification of the Fitted Formulae by Experimental Results. To verify the applicability of the fitted formulae in evaluating the structural field capacity of the bolted steel plates with different buckling restraint measures, the experimental results $\left(F_{\text {exp }}\right)$ of the previous experimental study [19] were also extracted and compared with the calculated results $\left(F_{\text {the }}\right)$. The comparison in Table 7 indicates that the maximum error is $10.6 \%$ and the average is $5.8 \%$. So the accuracy and effectivity of the fitted formulae are validated.

5.2. Recommended Size of Stiffeners. It is evident from the aforementioned study that the arrangement of stiffeners, especially the longitudinal stiffeners, can substantially improve the structural field capacity and restrict the lateral 
TABle 7: Comparison of the field capacities derived from the theoretical and experimental studies.

\begin{tabular}{lccc}
\hline Specimens & $F_{\text {the }}(\mathrm{kN})$ & $F_{\text {exp }}(\mathrm{kN})$ & Errors \\
\hline E4NN & 149.0 & 144 & $3.5 \%$ \\
E6NN & 268.6 & 266 & $1.0 \%$ \\
E4SN & 324.3 & 314 & $3.3 \%$ \\
E4MN & 513.3 & 464 & $10.6 \%$ \\
E4LN & 663.9 & 603 & $10.1 \%$ \\
E4SS & 338.3 & 318 & $6.4 \%$ \\
\hline
\end{tabular}

local buckling of the bolted steel plates. The efficiency of such improvement is highly related to the size of the stiffeners, so providing a recommended stiffener size to obtain a maximum enhancement with an economic consumption of stiffener steel is not only necessary, but also practical and useful.

In the Chinese steel structural specifications [26], when a transverse stiffener is employed in a double T-steel, its size is recommended as follows:

$$
\begin{aligned}
& b \geq \frac{h}{30}+40, \\
& a=\frac{b}{15},
\end{aligned}
$$

where $h$ is the clear height of the web plate of the double T-steel and $b$ and $a$, respectively, represent the width and thickness of the stiffener. Nevertheless, it only specifies the minimum geometric dimension of the stiffeners. So such recommended value is not convenient for utilization. And, furthermore, there is even no such recommended value for the stiffeners used for the bolted steel plates in steel jacketing.

In order to solve this problem, a parametric study of more models restricted by stiffeners in variable sizes was conducted. It is reasonable to use the value of $F_{2} / F$ to evaluate the efficiency of stiffener utilization, in which $F$ represents the total structural field capacity and $F_{2}$ represents the capacity enhancement beneficial from the buckling restraint of the stiffeners. Then, the relation between the value of $F_{2} / F$ and the dimensional parameters of stiffeners can be studied to optimize the stiffener size.

Figure 13(a) shows the relationship between $F_{2} / F$ and $a b / B t$, which represents the area ratio. It can be found that the efficiency of stiffener utilization $\left(F_{2} / F\right)$ is stable and relatively large when $a b / B t=0.1$. Figures $13(\mathrm{~b})$ and $13(\mathrm{c})$ respectively, show the relationship between $F_{2} / F$ and $a / t$ or $b / t$, which represents the ratio of the thickness or the breadth of the stiffeners to the thickness of the bolted steel plates, respectively. Similarly, $b / t$ and $a / t$ can be, respectively, recommended as 1.2 and 6 . And Figure 13(d) shows $F_{2} / F-b / a$ curve, which indicates that $b / a$ is suitable to be chosen as 5 . By comparing the recommended values in this study $(a b / B t$, $a / t, b / t$, and $b / a)$ and that in the Chinses steel structural specifications, the former are more specific and can provide guideline to the strengthening design practice of the bolted steel plates in steel jacketing.

\section{Conclusion}

By a comprehensive parametric study on the local buckling behaviour of the bolted steel plates with different buckling restraint measures, the following conclusions can be drawn:

(1) The local buckling behaviour of steel plates can be accurately simulated by the NLFEA program ABAQUS, if the suggested simulation procedure is followed.

(2) The arrangement of less bolt spacing, longitudinal stiffeners, and thicker steel plates can substantially improve the structural field capacity of the bolted steel plates. The first two restraint measures can also considerably decrease the lateral buckling deformation.

(3) The arrangement of transverse stiffeners can limit the lateral buckling deformation of the central region of the bolted steel plates, while it is less obvious in improving the structural field capacity.

(4) The local buckling of the bolted steel plates is insensitive to initial imperfection. And the field capacity and the growing trend of the lateral buckling deformation of the bolted steel plates with different initial imperfection are generally the same.

(5) The improvement of the structural field capacity due to the arrangement of longitudinal stiffeners can be divided into two parts: the yield strength capacity of the stiffeners and the capacity enhancement of the bolted steel plates beneficial from the buckling restraint of the stiffeners. And the proposed fitted formulae can evaluate the structural field capacity with satisfactory accuracy.

(6) To get a high efficiency of stiffener utilization, the area ratio $(a b / B t)$, the ratio of the breadth of stiffeners to the plate thickness $(b / t)$, and the breadth to thickness ratio of the stiffeners $(b / a)$ can be recommended as $0.1,6$, and 5 , respectively.

\section{Notations}

B: $\quad$ The width of steel plate

E: The elastic modulus of steel plate

$F_{0}: \quad$ The capacity of the bolted steel plates

$F_{1}$ : The yield strength of the longitudinal stiffeners

$F_{2}$ : The improvement of yield strength due to the restraint of the longitudinal stiffeners

$F_{\text {exp }}:$ The experimental results

$F_{\text {num }}:$ The numerical results

$F_{\text {the }}$ : The calculated results

$L: \quad$ The spacing of bolts

$a$ : The thickness of longitudinal stiffener

$b$ : The width of longitudinal stiffener

$f_{y}:$ The field capacity of stiffener

$h$ : The clear height of the web plate of a double T-steel

$t$ : The thickness of steel plate 


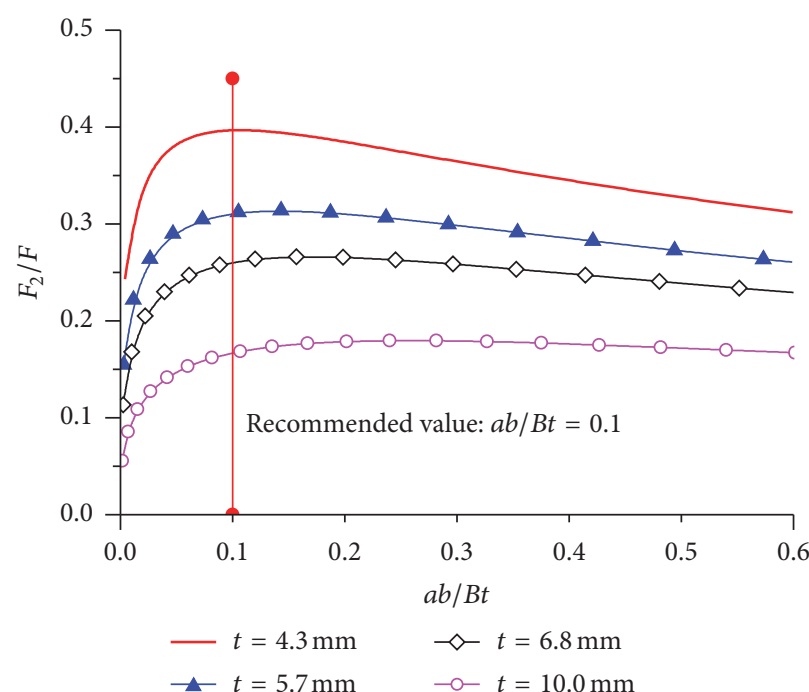

(a)

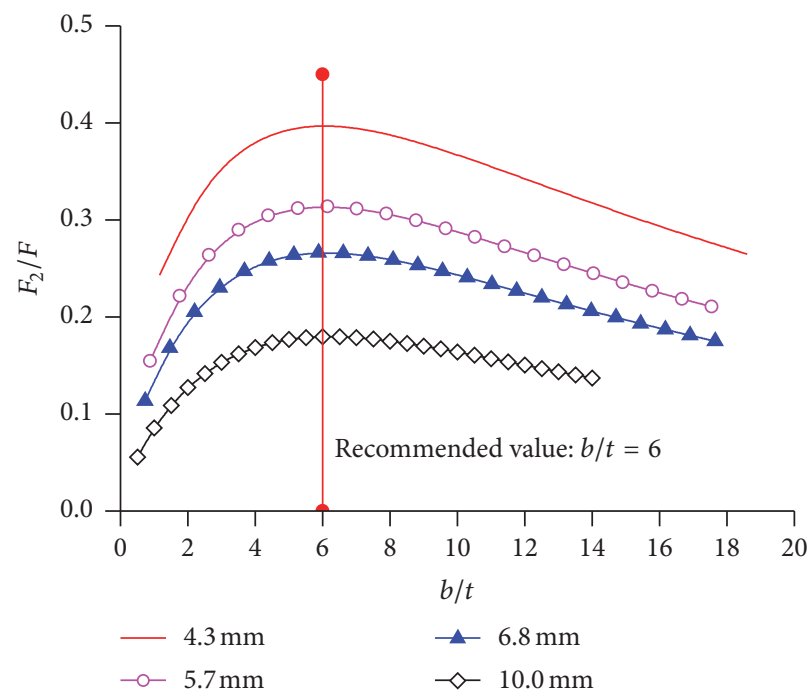

(c)

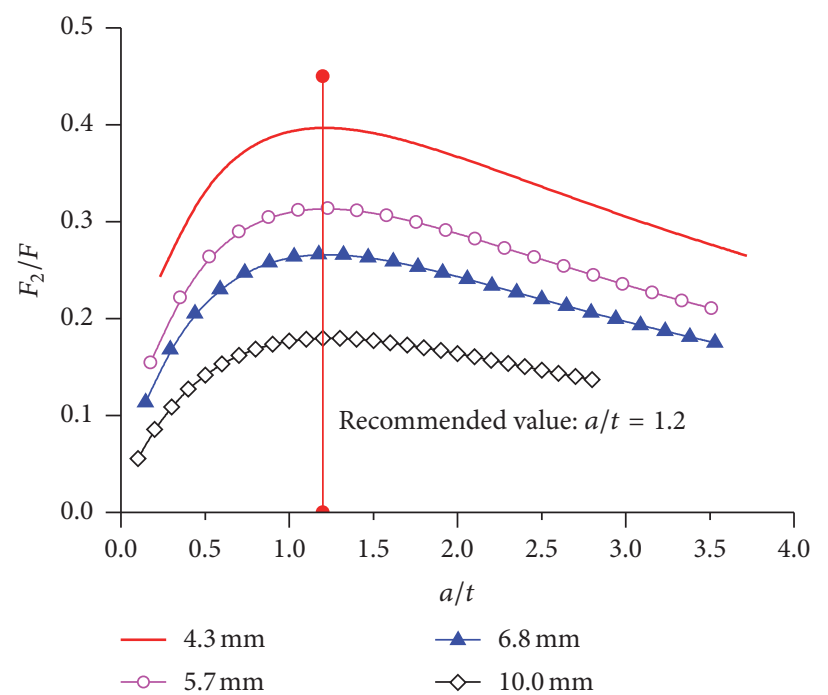

(b)

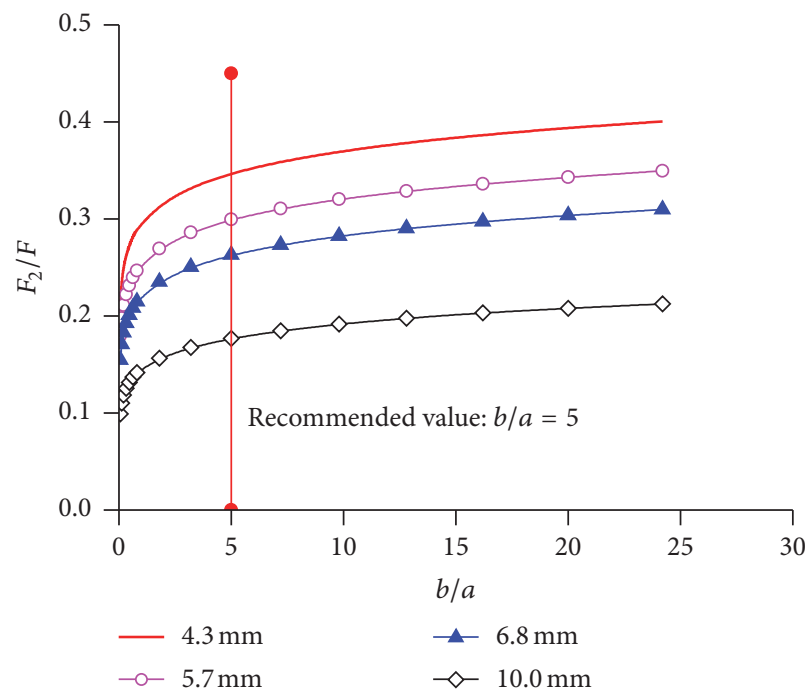

(d)

Figure 13: The relation between the value of $F_{2} / F$ and the geometric dimensional parameters of stiffeners: (a) $F_{2} / F-a b / B t$, (b) $F_{2} / F-a / t$, (c) $F_{2} / F-b / t$, and (d) $F_{2} / F-b / a$.

$\alpha: \quad$ The factor for the improvement due to transverse stiffeners

$\gamma_{0}, x, y$, and $z: \quad$ Parameters in fitting $F_{0}$ $\gamma_{2}, j, k, l, m$, and $n$ : Parameters in fitting $F_{2}$.

\section{Competing Interests}

The authors declare that there is no conflict of interests regarding the publication of this paper.

\section{Acknowledgments}

The research described here received financial support from the National Natural Science Foundation of China (Project no. 51408436).

\section{References}

[1] L. Wang, Post-compressed plates for strengthening preloaded reinforced concrete columns [Ph.D. dissertation], The University of Hong Kong, Hong Kong, 2013.

[2] S. A. Hamoush and S. H. Ahmad, "Debonding of steel platestrengthened concrete beams," Journal of Structural Engineering, vol. 116, no. 2, pp. 356-371, 1990.

[3] O. Buyukozturk, O. Gunes, and E. Karaca, "Progress on understanding debonding problems in reinforced concrete and steel members strengthened using FRP composites," Construction and Building Materials, vol. 18, no. 1, pp. 9-19, 2004.

[4] S. J. E. Dias and J. A. O. Barros, "Performance of reinforced concrete $\mathrm{T}$ beams strengthened in shear with NSM CFRP laminates," Engineering Structures, vol. 32, no. 2, pp. 373-384, 2010. 
[5] U. Ebead and H. Saeed, "Hybrid shear strengthening system for reinforced concrete beams: an experimental study," Engineering Structures, vol. 49, pp. 421-433, 2013.

[6] T. M. Roberts and H. Haji-Kazemi, "Strengthening of underreinforced concrete beams with mechanically attached steel plates," International Journal of Cement Composites and Lightweight Concrete, vol. 11, no. 1, pp. 21-27, 1989.

[7] R. K. L. Su and Y. Zhu, "Experimental and numerical studies of external steel plate strengthened reinforced concrete coupling beams," Engineering Structures, vol. 27, no. 10, pp. 1537-1550, 2005.

[8] A. Souici, J. F. Berthet, A. Li, and N. Rahal, "Behaviour of both mechanically connected and bonded steel-concrete composite beams," Engineering Structures, vol. 49, pp. 11-23, 2013.

[9] C. M. Foley and E. R. Buckhouse, "Method to increase capacity and stiffness of reinforced concrete beams," Practice Periodical on Structural Design and Construction, vol. 4, no. 1, pp. 36-42, 1999.

[10] R. K. L. Su, W. H. Siu, and S. T. Smith, "Effects of bolt-plate arrangements on steel plate strengthened reinforced concrete beams," Engineering Structures, vol. 32, no. 6, pp. 1769-1778, 2010.

[11] L. Z. Li, S. H. Lo, and R. K. L. Su, "Experimental study of moderately reinforced concrete beams strengthened with bolted-side steel plates," Advances in Structural Engineering, vol. 16, no. 3, pp. 499-516, 2013.

[12] D. J. Oehlers, N. T. Nguyen, M. Ahmed, and M. A. Bradford, "Transverse and longitudinal partial interaction in composite bolted side-plated reinforced-concrete beams," Structural Engineering and Mechanics, vol. 5, no. 5, pp. 553-563, 1997.

[13] K. Fukuyama, Y. Higashibata, and Y. Miyauchi, "Studies on repair and strengthening methods of damaged reinforced concrete columns," Cement and Concrete Composites, vol. 22, no. 1, pp. 81-88, 2000.

[14] Y. Xiao and H. Wu, "Retrofit of reinforced concrete columns using partially stiffened steel jackets," Journal of Structural Engineering, vol. 129, no. 6, pp. 725-732, 2003.

[15] J. Garzón-Roca, J. M. Adam, and P. A. Calderón, "Behaviour of RC columns strengthened by steel caging under combined bending and axial loads," Construction \& Building Materials, vol. 25, no. 5, pp. 2402-2412, 2011.

[16] Y. H. Chai, M. J. N. Priestley, and F. Seible, "Analytical model for steel-jacketed RC circular bridge columns," Journal of Structural Engineering, vol. 120, no. 8, pp. 2358-2376, 1994.

[17] S. T. Smith, M. A. Bradford, and D. J. Oehler, "Buckling tests on steel plates restrained at discrete points in the retrofit of reinforced concrete beams," Proceedings of the Institution of Civil Engineers: Structures and Buildings, vol. 146, no. 2, pp. 115-127, 2001.

[18] B. Uy and M. A. Bradford, "Local buckling of thin steel plates in composite construction: experimental and theoretical study," Proceedings of the ICE-Structures and Buildings, vol. 110, no. 4, pp. 426-440, 1995.

[19] L. Z. Li, C. J. Jiang, L. J. Jia, and Z. D. Lu, "Local buckling of bolted steel plates with different stiffener configuration," Engineering Structures, vol. 119, no. 7, pp. 186-197, 2016.

[20] A. S. Lubell, H. G. L. Prion, C. E. Ventura, and M. Rezai, "Unstiffened steel plate shear wall performance under cyclic loading," Journal of structural engineering New York, N.Y., vol. 126, no. 4, pp. 453-460, 2000.

[21] H. D. Wright, "Buckling of plates in contact with a rigid medium," Structural Engineer, vol. 71, no. 12, pp. 209-215, 1993.
[22] H. B. Ge and T. Usami, "Strength analysis of concrete-filled thin-walled steel box columns," Journal of Constructional Steel Research, vol. 30, no. 3, pp. 259-281, 1994.

[23] S. T. Smith, M. A. Bradford, and D. J. Oehlers, "Local buckling of side-plated reinforced-concrete beams. I: Theoretical Study," Journal of Structural Engineering, vol. 125, no. 6, article 622, 1999.

[24] S. T. Smith, M. A. Bradford, and D. J. Oehlers, "Unilateral buckling of elastically restrained rectangular mild steel plates," Computational Mechanics, vol. 26, no. 4, pp. 317-324, 2000.

[25] S. T. Smith, M. A. Bradford, and D. J. Oehlers, "Local buckling of side-plated reinforced-concrete beams. II: experimental study," Journal of Structural Engineering, vol. 125, no. 6, pp. 635-642, 1999.

[26] GB50017-2003, Code for Design of Steel Structures, China Architecture \& Building Press, Beijing, China, 2003. 

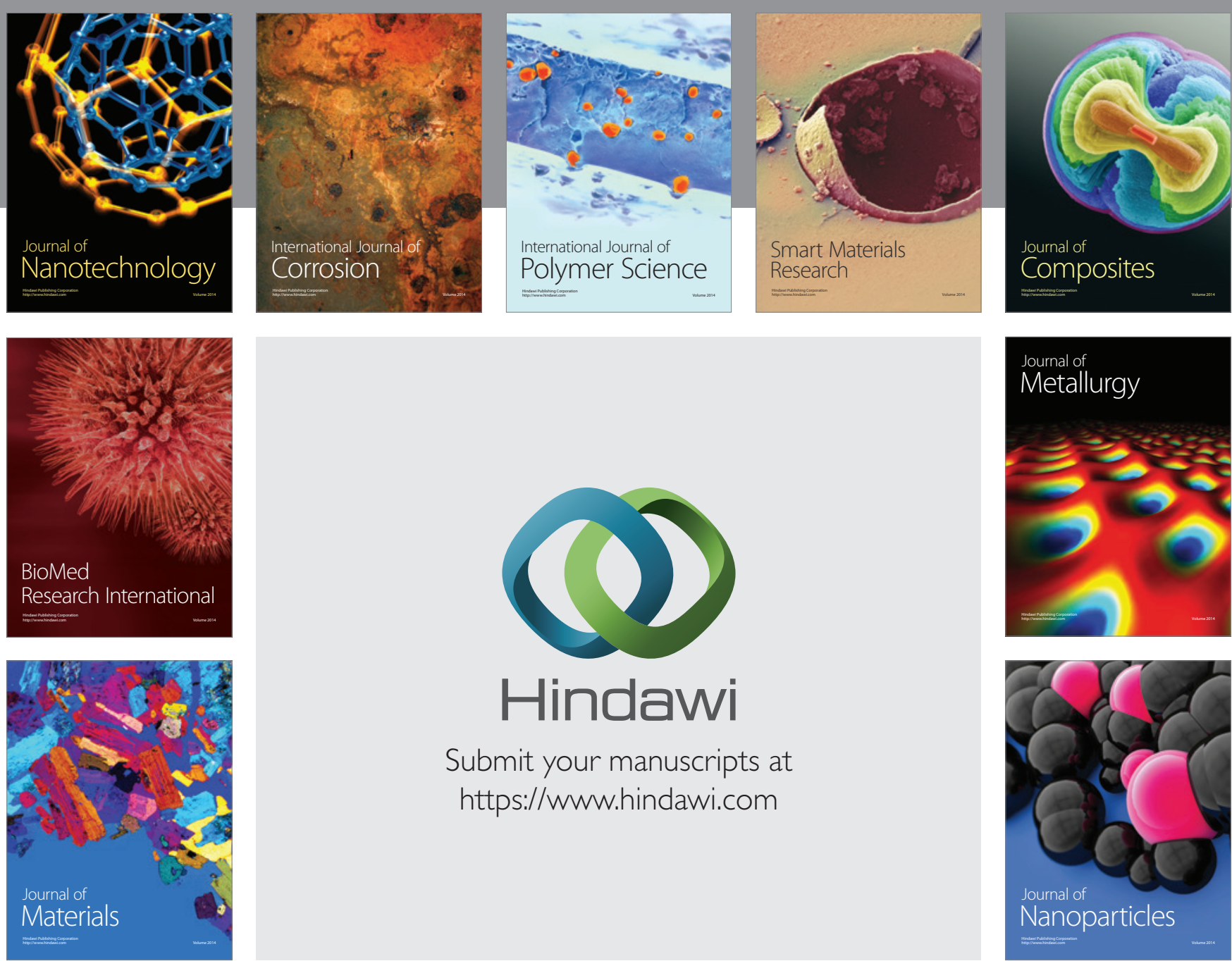

\section{Hindawi}

Submit your manuscripts at

https://www.hindawi.com

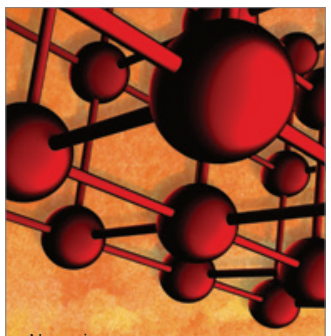

Materials Science and Engineering
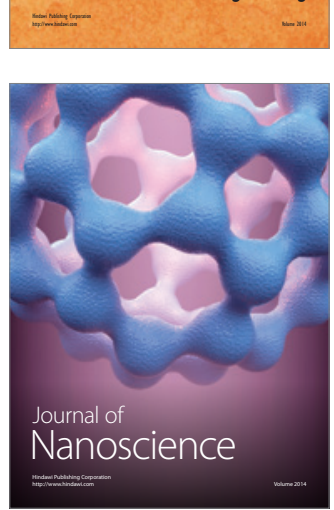
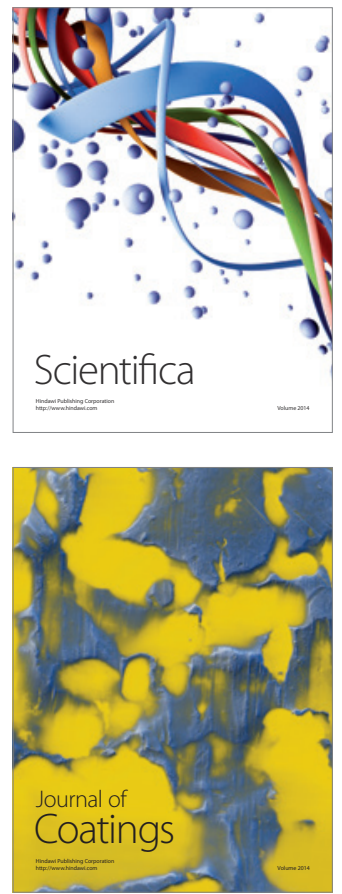
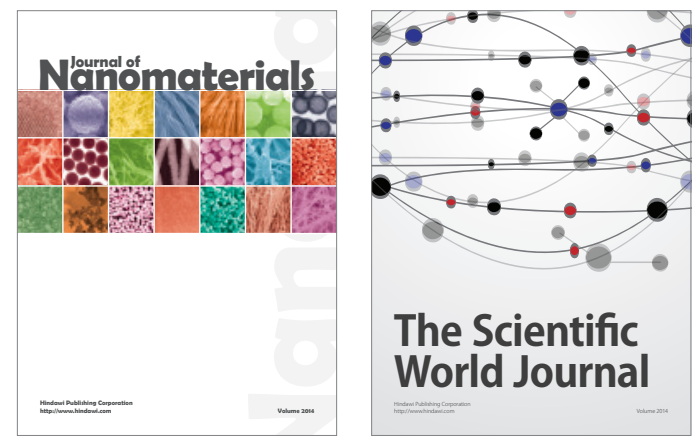

The Scientific World Journal
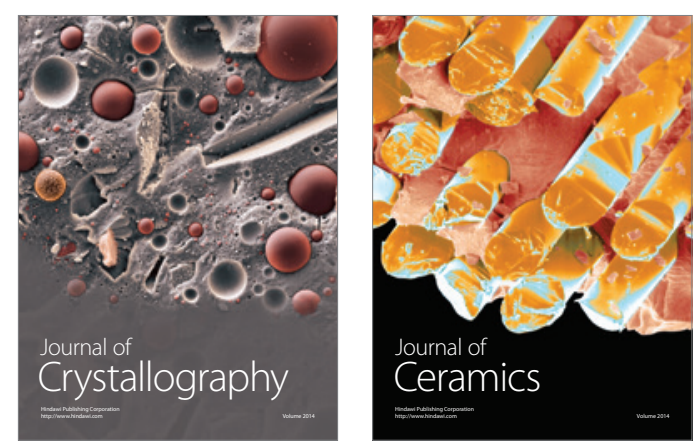
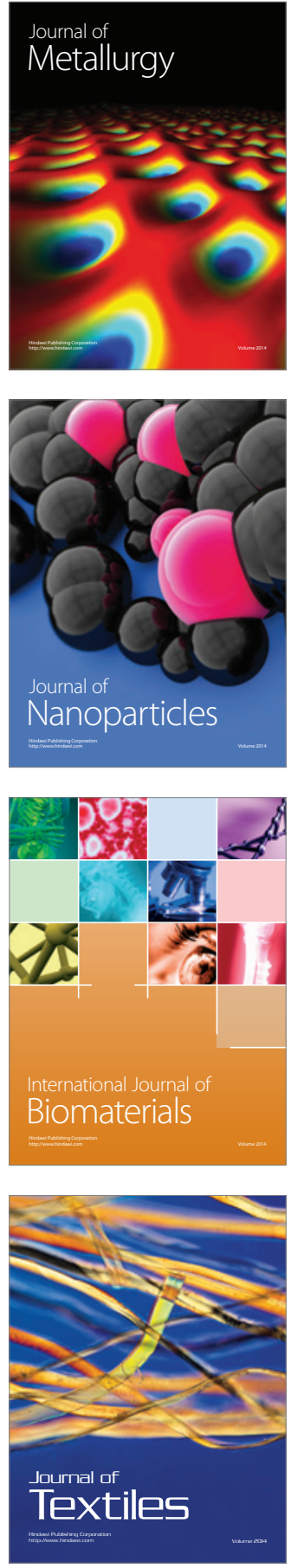